Li XF, Yu J, Li Y. Recent summer rainfall increase and surface cooling over Northern Australia since the late 1970s: A response to warming in the tropical Western Pacific. Journal of Climate 2013, 26(18), 7221-7239. Copyright:

C 2013 American Meteorological Society

DOI link to article:

https://doi.org/10.1175/JCLI-D-12-00786.1

Date deposited:

$18 / 12 / 2017$ 


\title{
Recent Summer Rainfall Increase and Surface Cooling over Northern Australia since the Late 1970s: A Response to Warming in the Tropical Western Pacific
}

\author{
XIAO-FENG Li \\ State Key Laboratory of Numerical Modeling for Atmospheric Sciences and Geophysical Fluid Dynamics, Institute \\ of Atmospheric Physics, Chinese Academy of Sciences, Beijing, China \\ JINGJING YU \\ National Meteorological Information Center, China Meteorological Administration, and State Key Laboratory of Numerical \\ Modeling for Atmospheric Sciences and Geophysical Fluid Dynamics, Institute of Atmospheric \\ Physics, Chinese Academy of Sciences, Beijing, China \\ YUN LI \\ Mathematics, Informatics and Statistics, CSIRO Climate Adaptation Flagship, Floreat, Western Australia, Australia
}

(Manuscript received 3 November 2012, in final form 1 March 2013)

\begin{abstract}
Rainfall over northern Australia (NA) in austral summer is the largest water source of Australia. Previous studies have suggested a strong zonal-dipole trend pattern in austral summer rainfall since 1950, with rainfall increasing in northwest Australia (NWA) but decreasing in northeast Australia (NEA). The dynamics of rainfall increase in NWA was linked to sea surface temperature (SST) in the south Indian Ocean and the rainfall decrease in NEA was associated with SST in the northeast Indian Ocean.

This study reports that, in contrast to a zonal-dipole trend pattern, a dominant wetting pattern over NA has recently been observed in the post- 1979 satellite era. The recent NA rainfall increase also manifests as the first leading mode of summer rainfall variability over the Australian continent. Further investigation reveals that SST in the tropical western Pacific (TWP) has replaced the SST in the south and northeast Indian Ocean as the controlling factor responsible for the recent NA rainfall increase. Direct thermal forcing by increasing TWP SST gives rise to an anomalous Gill-type cyclone centered around NA, leading to anomalously high rainfall. As such, the increasing SST in the TWP induces over $50 \%$ of the observed rainfall wetting trend over NA. The increased rainfall in turn induces land surface cooling in NA. This mechanism can be confirmed with results obtained from sensitivity experiments of a numerical spectral atmospheric general circulation model. Thus, increasing SST in the TWP has contributed much of the recent summer rainfall increase and consequently the surface cooling over NA.
\end{abstract}

\section{Introduction}

Rainfall over northern Australia (NA, north of $26^{\circ} \mathrm{S}$ ) in austral summer [December-February (DJF)] is the largest source of water for Australia, with more than $40 \%$ of the total annual rainfall over the whole Australian continent falling in NA during this single season. A strong zonal-dipole trend pattern in NA summer rainfall during

Corresponding author address: Dr. Jingjing Yu, NMIC, CMA, No. 46, Zhongguancun Nandajie, Haidian District, Beijing 100081, China.

E-mail: yujj@cma.gov.cn the second half of the twentieth century has been identified (e.g., Smith 2004; Shi et al. 2008; Taschetto and England 2009a). Rainfall increased in northwest Australia (NWA, west of $130^{\circ} \mathrm{E}$, north of $26^{\circ} \mathrm{S}$ ) and decreased in northeast Australia (NEA, east of $130^{\circ} \mathrm{E}$, north of $26^{\circ} \mathrm{S}$ ) (as shown in Fig. 5c in Smith 2004; Fig. 1a in Wardle and Smith 2004; Fig. 2e in Shi et al. 2008; Fig. 1b in Feng et al. 2013).

Various efforts have been made to understand the observed trend patterns in both NWA and NEA summer rainfall. Wardle and Smith (2004) suggested that the rainfall increase in NWA may be linked to stronger Australian summer monsoonal circulation forced by the temperature gradient between Australia and the surrounding oceans. 
Their argument was based on a low-resolution (R21L09) climate model simulation in which a reduction of land albedo by a factor of 4 was used to alter the temperature contrast. However, such a low-resolution model is known to be unable to fully capture the relevant covariances and nonlinear terms (Simmonds and Lynch 1992), the reduction in the prescribed land albedo, and the resulting surface temperature changes in Australia. These temperature changes were also much larger than what could be justified on the basis of current knowledge (Shi et al. 2008); so, the importance of land-ocean temperature contrast remains an open question. Rotstayn et al. (2007) highlighted the effect of anthropogenic aerosol change in the twentieth century on the increased rainfall trend in NWA. They reproduced an increased rainfall trend in NWA by including anthropogenic aerosol changes in a low-resolution GCM. Their results suggested that a strong impact of aerosols is mainly from massive Asian aerosol haze, which leads to changes in the meridional temperature and pressure gradients over the tropical Indian Ocean in the model, and so increases the tendency of monsoonal winds to flow toward Australia. However, as pointed out by Shi et al. (2008), the modeled rainfall trend in the GCM is based on an unrealistic relationship between Australian rainfall and eastern Indian Ocean sea surface temperature (SST), which suffers from a bias in the equatorial tropical Pacific cold tongue, penetrating too far into the eastern Indian Ocean; that is, in the presence of increasing aerosols, a significant SST increase occurs in the tropical eastern Indian Ocean and contributes to the modeled rainfall increase in NWA (Shi et al. 2008; Cai et al. 2010). The impact of aerosols on Australian rainfall is therefore still unclear. In examining the dynamics of the observed rainfall variability in NWA, Shi et al. (2008) found that the observed positive trend is closely related to the lower-tropospheric circulation and SST changes in the south Indian Ocean. Lin and $\mathrm{Li}$ (2012) found that the increasing trend in atmospheric upward motion induced by the increasing SST in the tropical Atlantic may also partially explain the observed rainfall trend in NWA.

Compared with causes of the rainfall increase over NWA, relatively little is known of the cause and mechanism of decreasing NEA rainfall. Two recent papers have shed some light on this topic. Shi et al. (2008) reported anomalously high sea level pressure (SLP) over much of the Australian continent; the anticyclonic circulation pattern is associated with southwesterly flows toward NEA, resulting in anomalously low rainfall in this region. J. Li et al. (2012) suggested that the Australian summer monsoon (AUSM) may have influenced NEA summer rainfall on both interannual and interdecadal time scales over the period from 1948 to 2006. They found that the decrease in NEA rainfall could be attributed to variability of the AUSM because of the continuous warming trend of SST in the Wharton Basin, located in the northeast Indian Ocean (J. Li et al. 2012).

Since the late 1970s, a series of abrupt decadal changes has occurred in atmospheric and oceanic regimes (e.g., Nitta and Yamada 1989; Trenberth 1990; Trenberth and Hurrell 1994; Mantua et al. 1997). Interdecadal change in properties in El Niño-Southern Oscillation (ENSO) in terms of the behavior shift of El Niño were observed in the late 1970s (e.g., Levitus et al. 1994; Zhang et al. 1998; Zhang and Busalacchi 2005). Recent studies have shown that central Pacific El Niño events (i.e., ENSO Modoki) have occurred more frequently since 1978 (e.g., Ashok et al. 2007; Kug et al. 2009). The influence of these abrupt decadal changes can be seen in regional rainfall patterns around the world. For instance, rainfall changes over east China since the late 1970s have been characterized as a wetting trend over the mid-lower Yangtze River valley and a drying trend over the Yellow River valley, a pattern known as "southern flooding and northern drought" in China (e.g., Yatagai and Yasunari 1994; Nitta and Hu 1996; Gong and Ho 2002; Hu et al. 2003; $\mathrm{Yu}$ and Zhou 2007; Zhu et al. 2007); rainfall characteristics in India (e.g., Kumar et al. 1999) and Korea (e.g., Ho et al. 2003) also shifted from "dry" to "wet" around this period; the increase in Sahel rainfall has been attributed to decadal-scale variability in global SST (e.g., Hoerling et al. 2006; Cook 2008); ocean temperature patterns in the tropics and subtropics may change in ways that will lead to significant changes in rainfall patterns (e.g., Xie et al. 2010); and ENSO Modoki events appear to drive a large-scale decrease in rainfall over northwestern and northern Australia in autumn (March-May) and spring (SeptemberNovember) (e.g., Taschetto and England 2009b). A natural question is therefore whether the rainfall trend of NA still exists as a zonal-dipole pattern after the abrupt decadal changes in atmospheric and oceanic circulations in the late 1970s.

In fact, the zonal-dipole trend pattern in NA summer rainfall (NASR) has changed into a dominant wetting trend over much of NA since the late 1970s (Fig. 1a). The current study therefore focuses on the dynamic mechanism driving this increasing trend in NASR since the late 1970s. Given that the quality of observational data improved because of the introduction of satellite data around 1979 (e.g., Martin and Scherer 1973; Kistler et al. 2001; Menzel 2001), we focus on the post-1979 satellite era. The remainder of this paper is organized as follows. Section 2 presents the data, methods, and a brief introduction of the numerical spectral atmospheric general circulation model (AGCM) used in this study. In section 3 , we present the observed summer rainfall 
a) $1979-2010$
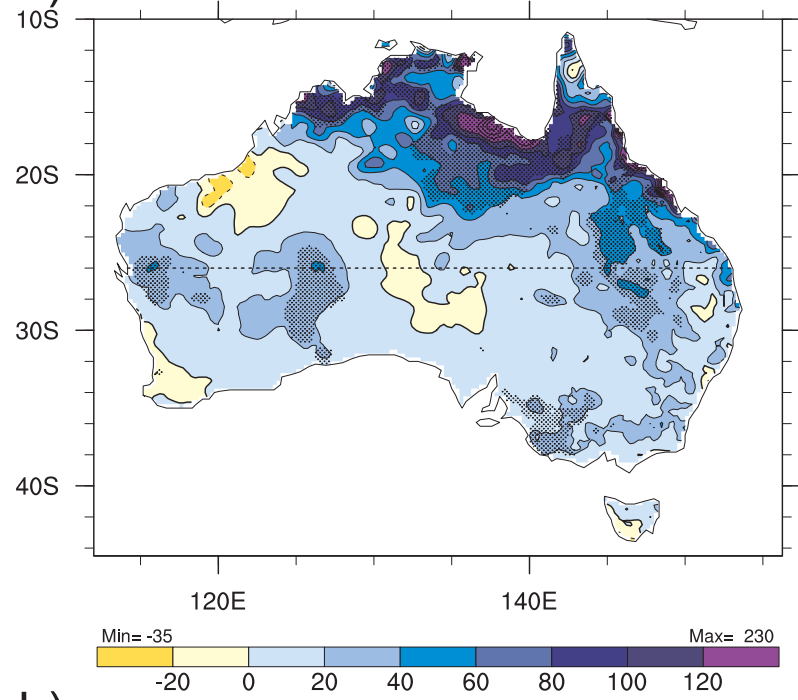

b)

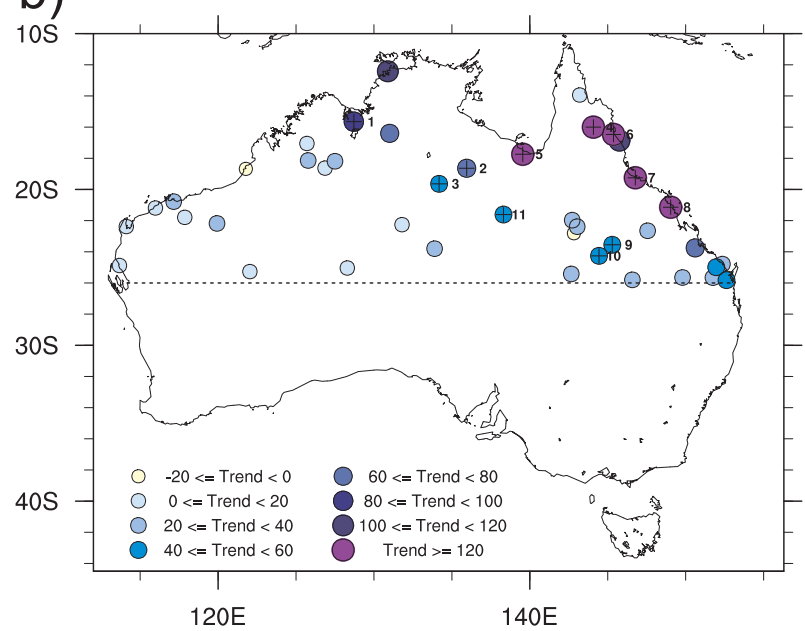

c)

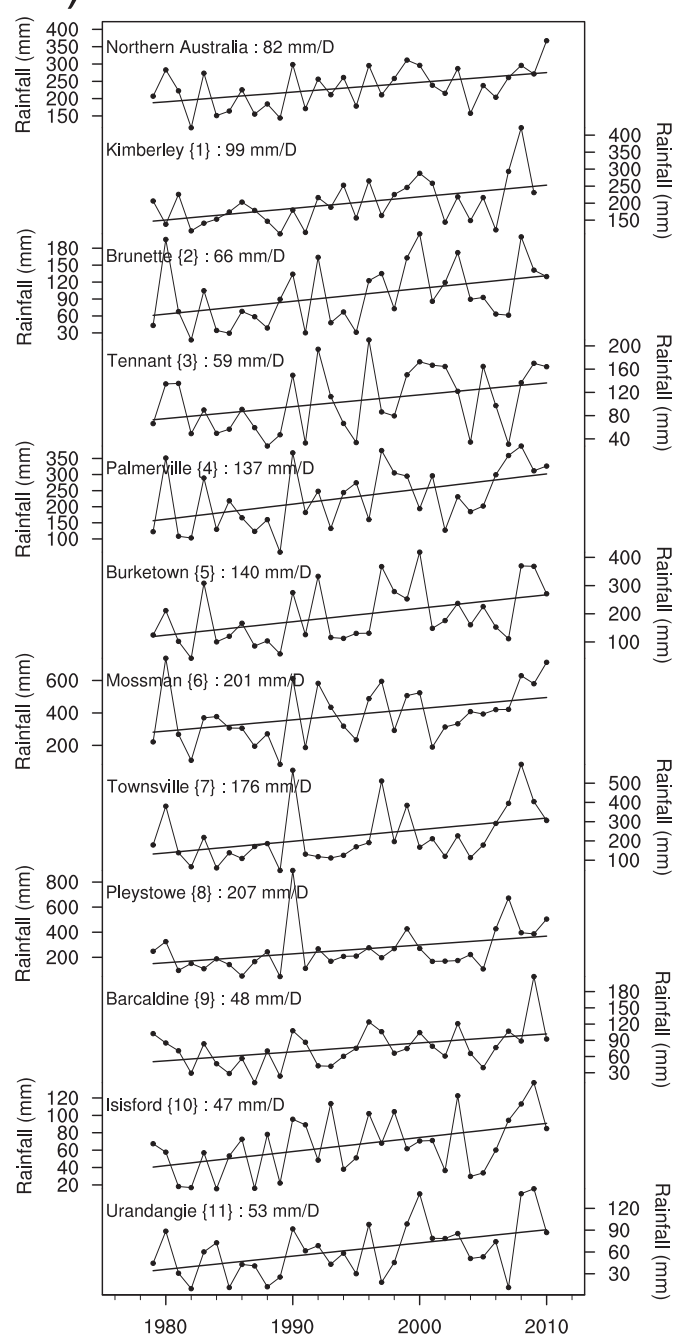

FIG. 1. Spatial pattern of austral summer rainfall trend ( $\mathrm{mm} \mathrm{decade}^{-1}$ ) over the 32 years 1979-2010 (a) based on the NCC-BOM gridded rainfall data and (b) based on the station rainfall data. (c) Time series (dotted curves) and linear trends (straight lines) of the summer NASR and 11 selected NA high-quality stations. All these 12 time series contain statistically significant (at the 0.05 level) positive trends with their values listed. The effective sample sizes (not shown) are reestimated according to Eq. (1) for testing the significance of trend. Station label numbers in parentheses match the labels in (b). Contour interval in (a) is 20; thin black (thin dashed) contours denote positive (negative) trends; the bold black contour is zero. Trends significant at the 0.05 level are stippled with little black dots in (a) and for stations marked by the plus symbol in (b).

trends over Australia after 1979. We show that there is a significant dominant wetting pattern over NA. The increase in NASR manifests as the variability in the first leading mode of summer rainfall over the Australian continent. In section 4, we explore the relationship between AUSM and NASR. We show that AUSM has no consistent trend and therefore cannot explain the increase of NASR. In section 5, we explore NA rainfall variability and the trend associated with changes in SST over the tropical eastern Indian and western Pacific Oceans. We find that increasing SST in the tropical western
Pacific (TWP) may induce more than $50 \%$ of the observed rainfall trend in NA. We propose a mechanism that the direct thermal forcing induced by increasing SST in the TWP gives rise to an anomalous Gill-type cyclone over much of the Australian continent with a center over NA; this leads to anomalously high rainfall in NA. The high rainfall then results in the cooling of NA land surface by reducing the incoming solar radiation and increasing the surface evaporation. This mechanism is supported in section 6 with results obtained from sensitivity experiments using a numerical spectral AGCM. 
Finally, the conclusions and discussions are presented in section 7 .

\section{Data and methods}

a. Data

The rainfall data analyzed here were provided by the National Climate Centre (NCC) of the Australian Bureau of Meteorology (BOM) and consist of gridded data on a $0.25^{\circ} \times 0.25^{\circ}$ grid. These are described by Lo et al. (2007), who indicated their confidence in the validity of these gridded rainfall analyses after 1948. The index of NA summer rainfall (NASRI) is defined as the average summer (DJF) rainfall totals in NA over the 32-yr period from 1979 to 2010, which was generated from the BOM website (http://www.bom.gov.au/cgi-bin/ climate/change/timeseries.cgi). High-quality station rainfall data at 42 stations over NA from a subset of the entire network in Australia (Haylock and Nicholls 2000) were also used in this study.

The SST data are the improved National Oceanic and Atmospheric Administration (NOAA) extended reconstructed SST version 3b (ERSST V3b) data (Smith et al. 2008 ) with a resolution of $2^{\circ} \times 2^{\circ}$ gridded points, downloaded from the NOAA website (http://www.ncdc.noaa. gov/ersst/). The Niño-3.4 index is used to indicate the variability of ENSO; it is defined as the average SST over the area $5^{\circ} \mathrm{N}-5^{\circ} \mathrm{S}, 170^{\circ}-120^{\circ} \mathrm{W}$ from ERSST V3b. An index of TWP (TWPI) was defined as the averaged SST over the TWP region $\left(5^{\circ} \mathrm{S}-10^{\circ} \mathrm{N}, 120^{\circ}-160^{\circ} \mathrm{E}\right)$. Two different monthly AUSM indices (AUSMIs) were employed to examine the relationship between AUSM variability and the NA wetting trend: one is defined by $\mathrm{Li}$ and Zeng (2000, 2002, 2003), available online (at http://jp.lasg.ac.cn/dct/page/65582), the other is given by Hung and Yanai (2004). Monthly gridded data for wind and sea level pressure (SLP), skin temperature (SKT), total cloud cover (TCDC), sensible heat net flux (SHNF), and surface latent heat net flux (SLHNF) were obtained from National Centers for Environmental Prediction (NCEP)/Department of Energy Global Reanalysis 2 (NCEP-2) data. All these data cover the period from January 1979 to February 2011, and the anomalies were calculated relative to the climatology for the period 1981-2010.

\section{b. Methods}

Empirical orthogonal function (EOF) analysis was used to identify the dominant variability patterns of Australian summer rainfall. We used a covariance EOF, and the spatial patterns of the domain modes were obtained by regressing gridpoint anomalies of Australian summer rainfall onto the standardized time series of
EOFs. Linear regression was used to estimate the linear trend in both observed rainfall and specific climate modes (e.g., AUSM). The regression coefficient or slope was used to represent the linear trend. Correlation and partial correlation were also employed to estimate the influence of a specific climate mode to the NA wetting trend.

Atmospheric and oceanic climate data are often autocorrelated; for example, NA rainfall has considerable year-to-year persistence (Simmonds and Hope, 1997) and tropical SSTs are documented to have strong persistence on interdecadal time scales (e.g., Y. Li et al. 2012). When data are autocorrelated, statistics used to test the significance of a trend in individual climate variables (and of the correlation between two climate variables) behave as if the sample size were less than the number of data points $N$. One way to deal with this is to determine an "effective sample size" and an "effective number of degrees of freedom," which is used to test the significance of a trend and correlation.

Following the standard regression (e.g., Santer et al. 2000), the least squares linear regression estimate of the trend in time series $X(t), b$, minimizes the squared differences between $X(t)$ and the regression line $\hat{X}(t)$, defined as

$$
\hat{X}(t)=a+b t, \quad t=1, \ldots, N .
$$

The regression residuals, $e(t)$, are defined as

$$
e(t)=X(t)-\hat{X}(t), \quad t=1, \ldots, N .
$$

Whether a trend in $X(t)$ is significantly different from zero at the $\alpha$ level is tested by using the Student's $t$ test applied to the ratio between the estimated trend and its standard error:

$$
T=\frac{b \sqrt{\sum_{t=1}^{N}(t-\bar{t})^{2}}}{\sqrt{\frac{1}{N_{\text {eff }}-2} \sum_{t=1}^{N} e(t)^{2}}} .
$$

Here, statistic $T$ is distributed as the Student's $t$ test with $N_{\text {eff }}-2$ degrees of freedom, and

$$
N_{\mathrm{eff}} \approx N \frac{1-R_{1}}{1+R_{1}}
$$

is the estimation of the effective number of the sample size (e.g., Bartlett 1935; Zwiers and Storch 1995) by taking into account the autocorrelation based on $R_{1}$, the lag- 1 autocorrelation calculated from the observed data $X(t)(t=1,2, \ldots, N)$. For the NASRI over the 1979-2010 
period, $N_{\text {eff }} \approx N=32$ and $R_{1}=-0.029$, indicating that there is no significant year-to-year persistence in NASRI in the recent 3 decades. In contrast, for the TWP index, $N_{\text {eff }} \approx N / 3$ and $R_{1}=0.464$, implying a strong autocorrelation in SSTs in the TWP region.

The significance of correlations between two autocorrelated time series of climate variables was tested by using adjusted degrees of freedom via an effective number of degrees of freedom $N_{\text {edof }}$ estimated by the modified Chelton method (e.g., Pyper and Peterman 1998; Y. Li et al. 2012). The $N_{\text {edof }}$ can be given by the theoretical approximation

$$
N_{\mathrm{edof}} \approx \frac{N}{1+2 \sum_{i=1}^{N} \frac{N-i}{N} R_{\mathrm{XX}}(i) R_{\mathrm{YY}}(i)},
$$

where $R_{\mathrm{XX}}(i)$ and $R_{\mathrm{YY}}(i)$ are the autocorrelations of two sampled time series, $X(i)$ and $(i)(i=1, \ldots, N)$. Theoretically, $N_{\text {edof }}$ should not be bigger than the sample size $N$ even when both the time series $X$ and $Y$ are random. In practice, the estimation of $N_{\text {edof }}$ can be bigger than $N$. Therefore, we restrict the maximum estimated value of $N_{\text {edof }}$ to be less than or equal to $N-2$ (i.e., the degree of freedom of $t$ test for the significance of a correlation between two independent samples). Given $N_{\text {edof }}$, the critical value for the null hypothesis that the correlation between time series $X$ and $Y$ is different from zero at the $\alpha$ significant level can be derived using the $t$ distribution with $N_{\text {edof }}$ for either one- or two-tailed tests (Zar 1984, p. 309):

$$
R_{\text {crit }}=\sqrt{T_{\alpha, N_{\text {edof }}}^{2} /\left(T_{\alpha, N_{\text {edof }}}^{2}+N_{\text {edof }}\right)} .
$$

When the correlation exceeds the critical value $R_{\text {crit }}$, the null hypothesis (i.e., the correlation between $X$ and $Y$ is 0 ) must be rejected, and this correlation is considered significant at the corresponding $\alpha$ level. Here, for testing the significance of the correlation between NASRI and TWPI in the 32-yr period (1979-2010), $N_{\text {edof }}=20$.

The contribution of a specific climate mode (e.g., AUSM) to the wetting trend of NA was judged by the method of Nicholls (2010), except the effective number of the sample size was reestimated using Eq. (1). We calculated the partial correlations between rainfall and the year of observation by removing the influence of the index of a specific climate mode (e.g., AUSM). The correlation value between rainfall and the year of observation indicates the significance of the linear trend of the rainfall; value $\geq 35$ or $\leq-35$ are significant at the 0.05 level based on a Student's $t$ test for a time series with 32 independent samples (i.e., for the NASRI over the $1979-2010$ period, $N_{\text {eff }}=30, N_{\text {edof }}=N_{\text {eff }}-2=30$ ). If the partial correlations, after removing the variations in the specific climate mode, are close to 0 , then this means that much of the rainfall trend is related to the trend in that climate mode; otherwise, it means that the rainfall trend is unlikely to be controlled by that climate mode.

To further quantify the contribution of a specific climate mode (e.g., AUSM) to the NA rainfall wetting trend, the year-to-year differences (also known as firstorder differences) of NA rainfall was regressed onto that of the climate mode index. The slope of this regression is defined as the sensitivity of rainfall to the climate mode, which represents the response of NA rainfall (in millimeters) to one unit variation of the climate mode index on interannual time scales. Assuming that the relationship derived from the year-to-year values operates on multidecadal time scales as well, this sensitivity can then be used to estimate the NA rainfall increase that could be associated with the observed trend in the climate mode (Nicholls 2010). This approach removes the possibility that any relationship between the climate mode index and the rainfall is simply due to the trends in the variables rather than reflecting a relationship that works on all climate time scales (Nicholls 2010).

\section{c. Model description}

To verify whether the NA rainfall trend is driven by changes in SST, a numerical model was used in this study: the spectral AGCM developed at the State Key Laboratory of Numerical Modeling for Atmospheric Sciences and Geophysical Fluid Dynamics (LASG), Institute of Atmospheric Physics (IAP), Chinese Academy of Sciences (CAS), Beijing, China. This model has nine levels in the vertical and is rhomboidally truncated at wavenumber 42 in the horizontal [i.e., the Spectral Atmosphere Model of IAP LASG (SAMIL)-R42L9 version] (e.g., Wu et al. 1997, 2003, 2007). The early version of this model is designed by Botjrke (1974) and developed by Simmonds (1985). This numerical model can simulate well the main characteristics of the observed climatology, including sea level pressure, precipitation, specific humidity, geopotential height, temperature, and winds (e.g., Wu et al. 2003, 2012).

\section{Observed NA summer rainfall trend and variability since 1979}

\section{a. Australian summer rainfall trend}

Figure 1 shows the regional rainfall trend over the Australian continent in DJF since 1979. It is evident that there is a dominant wetting trend over NA except in a small part of southwest NA (Fig. 1a). The significant rainfall increasing trends are mainly centered over the NA coastal area, extending to the north of New South 
a) EOF1 ( $41.0 \%)$

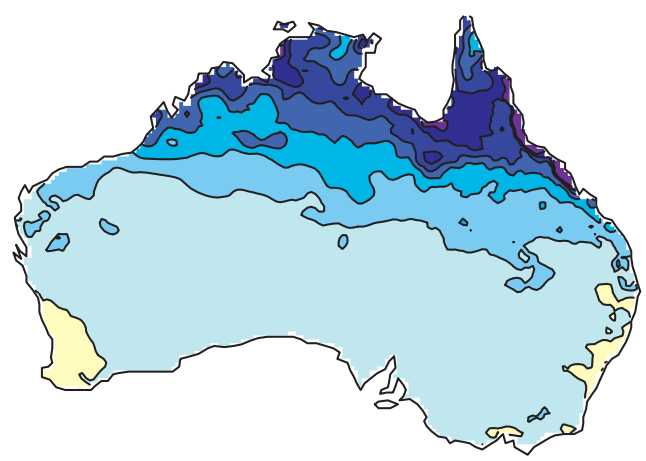

b) EOF2 ( $12.7 \%)$

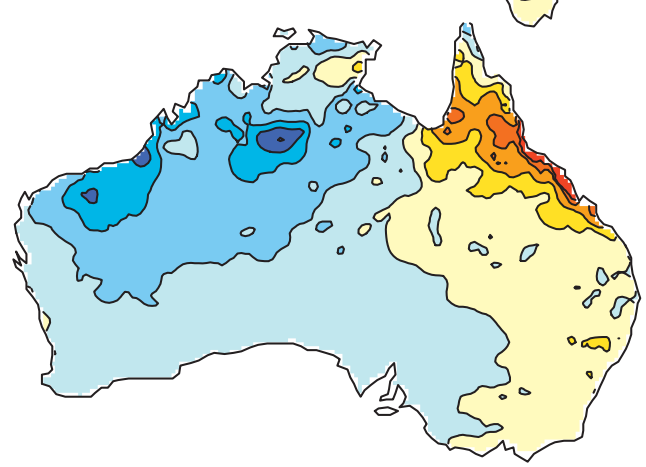

c) EOF3 (6.7\%)

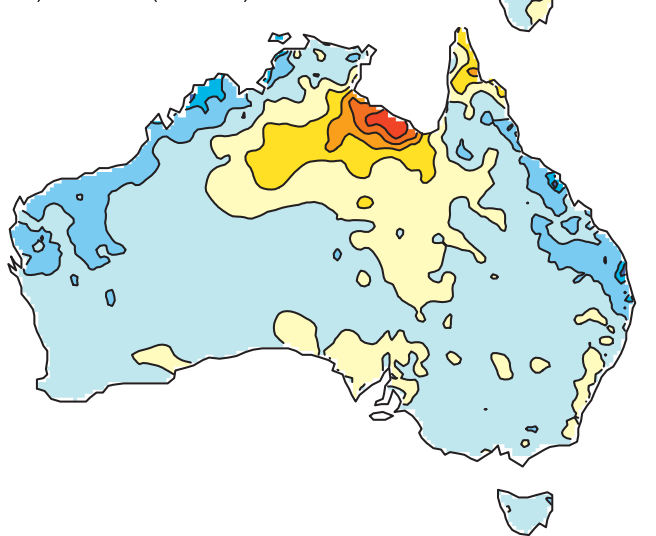

d) $r=0.94$

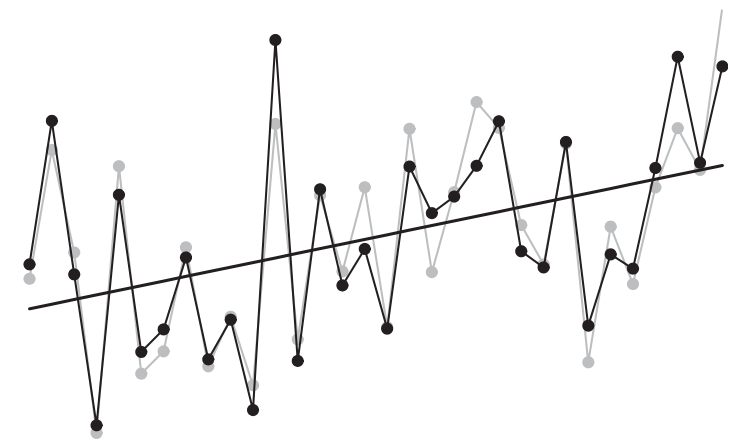

e) $r=0.14$

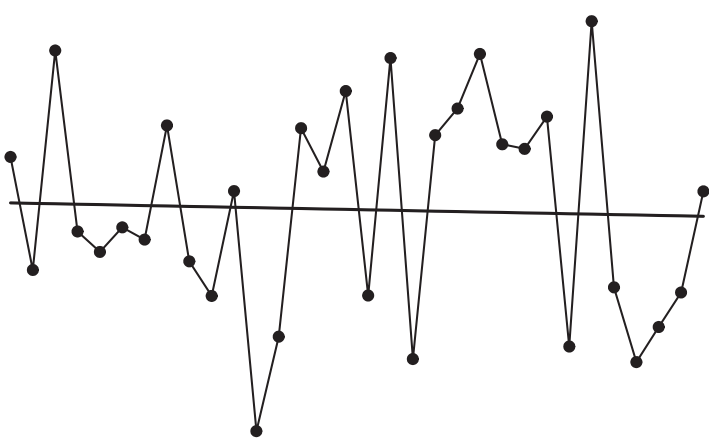

f) $r=0.23$

FIG. 2. EOFs of the austral summer rainfall anomaly over Australia for the period 1979-2010. (a)-(c) Regression maps of rainfall ( $40 \mathrm{~mm}$ decade ${ }^{-1}$ per contour interval; warm and cool colors denote positive and negative, respectively) based on the normalized time series of EOF1, EOF2, and EOF3, respectively. (d)-(f) Respective normalized time coefficients (curves with black circles) and linear trends (black straight lines). Only the EOF1 time coefficients contain a significant linear trend with a slope of 1.4 standard unit decade ${ }^{-1}$, exceeding the $95 \%$ confidence level. Effective sample sizes (not shown) are reestimated according Eq. (1). EOF1 time coefficients and the normalized NASR time series (curves with gray circles) are overlaid in (d). Correlation values between the time series of NASR and the EOF time coefficients $(r)$ are as high as 0.94 .

Wales, with the maximum positive trend reaching about $230 \mathrm{~mm} \mathrm{decade}^{-1}$. The average NA rainfall (Fig. 1c) has a positive trend with a slope of $82 \mathrm{~mm} \mathrm{decade}^{-1}$, significant at the 0.05 level $\left(N_{\text {eff }} \approx 32\right)$. The dramatic increasing of summer rainfall in NA can also be demonstrated from individual instrumental records. As shown in Fig. 1b, there is an overall increasing trend in rainfall observed at 41 (out of 42) high-quality stations over NA. In particular, the rainfall series of 11 stations over central and eastern NA show increasing trends, and all are significant at 
a)

b)
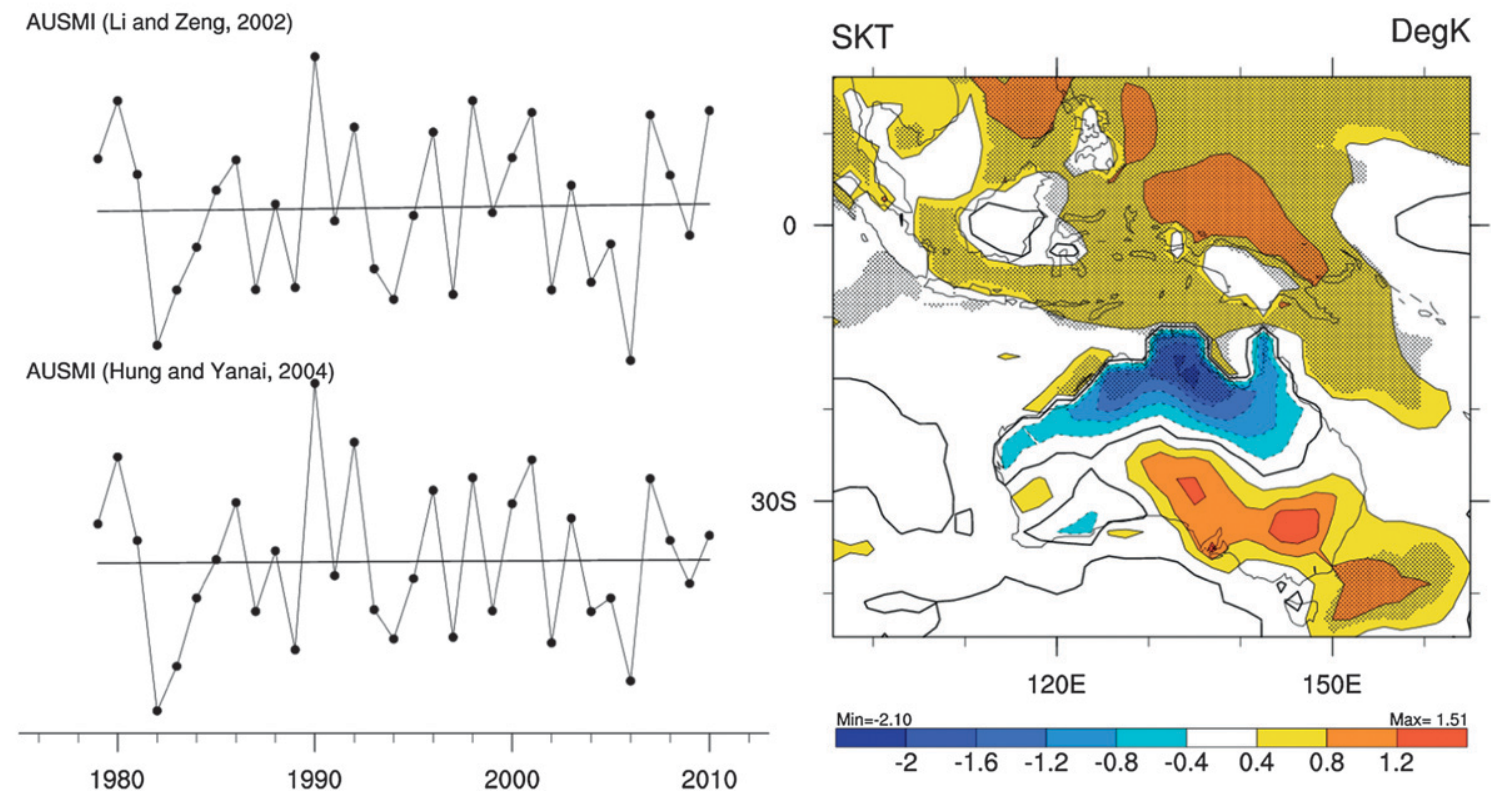

FIG. 3. (a) Normalized time series (curves with black circles) of the two types of AUSMI and their respective linear trends (black straight line) during 1979-2010. None of these two AUSMI have an evident linear trend. (b) Trend map of SKT during 1979-2010. Contour interval is $0.4 \mathrm{~K}$; thin black (thin dashed) contours denote positive (negative) values, and bold black contours denote zero. SKT anomalies in excess of $\pm 0.4 \mathrm{~K}$ are color shaded, and areas with significant trends at the 0.05 level are stippled with little black dots. Effective sample sizes (not shown) are reestimated according to Eq. (1) for testing the significance of trend.

the 0.05 level (Fig. 1c). Among them, two of the wettest stations-Mossman and Pleystowe- even increased 201 and $207 \mathrm{~mm} \mathrm{decade}^{-1}$, respectively. Thus, positive trends have dominated the whole of NA during the past 32 years.

The above-mentioned positive rainfall trend pattern in the 1979-2010 period differs from the well-known zonal-dipole trend structure of NA rainfall in the second half of the twentieth century (1951-2000) (e.g., Shi et al. 2008; Taschetto and England 2009a). The main difference is the remarkable increase of rainfall over NEA since 1979, rather than the decrease of rainfall over NEA in the 1951-2000 period. During 1951-2000, the summer rainfall over NEA was decreasing, with a maximum negative rainfall trend with slope $-70 \mathrm{~mm} \mathrm{decade}^{-1}$. However, NEA summer rainfall increases in 1979-2010, with a maximum positive rainfall trend above $200 \mathrm{~mm}$ decade $^{-1}$, as mentioned above. In both periods, the rainfall trends over NWA are positive except in the small patch over central NWA, and they do not change as drastically as those over NEA. So, the dramatic increase in NEA rainfall since the late 1970s is a large transformation that changes the NA dipole trend pattern into a dominant positive trend pattern in recent decades.

\section{b. Dominant modes of Australian summer rainfall}

An EOF analysis is conducted to examine the dominant modes of Australian summer rainfall variability and their connection with the NA wetting trend. Figure 2 shows the first three EOF modes of NA summer rainfall variability over the past three decades, which can be distinguished from each other according to the rule of thumb of North et al. (1982).

The key feature of the EOF analysis is that the overall increasing trend pattern in NA summer rainfall is captured well by the first leading mode (EOF1). The spatial pattern of EOF1 (Fig. 2a) is similar to the spatial pattern of the summer rainfall trend shown in Fig. 1a. EOF2 (Fig. 2b) and EOF3 (Fig. 2c) represent dipole and tripole modes, respectively. The variation of EOF1 explains about $41 \%$ of the total variance of Australian rainfall. Treating the rainfall over NA as a whole, EOF1 can explain over $88 \%$ of the variance of the average NA rainfall variability. The correlation between the time series of EOF1 and NASR reaches 0.94 (Fig. 2d), which is much higher than the correlation between NASR and EOF2 ( $r=0.14$, Fig. 2e) and EOF3 ( $r=0.23$, Fig. 2 f). In addition, EOF1 is the only one out of the three EOF leading modes with a significant linear trend; the 
variation of the other two modes is essentially the interannual variability over NA. Therefore, the dominant increase of NA summer rainfall corresponds to the first leading mode of summer rainfall variability over the Australian continent.

\section{Australian summer monsoon, NA wetting and cooling trend}

\section{a. Australian summer monsoon and NA wetting trend}

As one of the tropical monsoon regions of the world (e.g., Li and Zeng 2002, 2003; Wang 2006), NA receives much of its precipitation from AUSM during the summer months (e.g., McBride 1987; Manton and McBride 1992). Wardle and Smith (2004) suggested that the intensity of AUSM might be an important factor driving the zonal-dipole trend pattern of NA summer rainfall for the period 1950-2000. Could AUSM have then contributed to the recent increase in NA rainfall after the late 1970s? This section examines the potential contribution of AUSM to the recent increase in NA rainfall.

To proceed, we employed two different AUSM indices by Li and Zeng $(2000,2002,2003)$ and Hung and Yanai (2004). It is found that the variation of NA rainfall is closely connected to that of AUSM. The correlations between two AUSMIs and NASRI are 0.59 and 0.51, respectively. They are both significant at the 0.05 level. After removal of the linear trend, the correlations between these AUSMIs and NASRI increased to 0.64 and 0.56 , respectively. This gives us greater confidence that there is a close physical link between NASR and AUSM on interannual variability. A stronger (weaker) AUSM brings more (less) rainfall to NA. However, AUSM contributes little to the recent linear increase in NA summer rainfall because it is not significantly trending up in recent variability; none of the correlation coefficients of two AUSMIs with year exceeds 0.03 (Fig. 3a). The absence of an increase trend in AUSM can also be demonstrated in terms of the variation of land-sea thermal contrast between Australia and the adjacent tropical ocean (e.g., Webster 1987; Webster and Tomas 1998; Hung and Yanai, 2004). Typically, a warmer NA land with a cooler neighboring ocean will induce a stronger AUSM, and vice versa. But, as shown in Fig. 3b, the linear trend of skin temperature around NA has shown a cooling trend over NA land and a warming trend over the adjacent TWP. Such a land-sea contrast is supposed to induce divergence over NA, thereby reducing sea breezes from TWP to NA, and thus weaken the AUSM system. Hence, the observed land-sea thermal contrast cannot intensify AUSM, and a nonintensified AUSM is unlikely to bring more rainfall to NA. a) NA-SKT $(R Y=-0.35)$



b) NASR (RY=0.45)

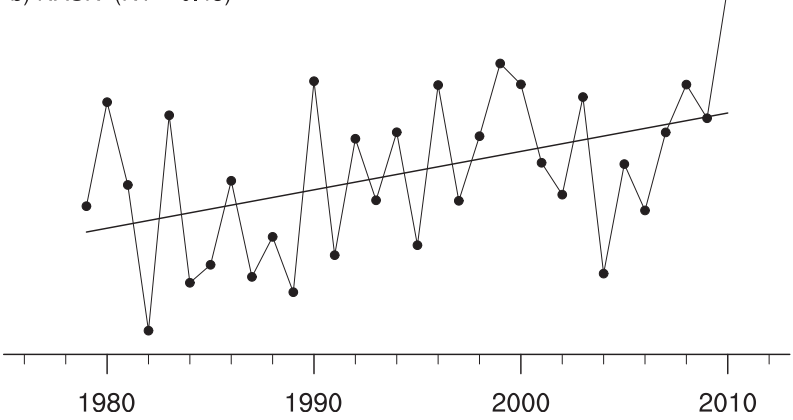

FIG. 4. Normalized time series (curves with black circles) of (a) NA averaged SKT and (b) NASR and their respective linear trends (straight lines) in austral summer during 1979-2010. Effective sample sizes (not shown) are reestimated according to Eq. (1), which gives; $N_{\text {eff }}=32$ for both time series. The RY is the correlation between the time series and year; $|R Y| \geq 0.35$ indicates a significant linear trend for a time series with 32 dependent sample sizes.

\section{b. Cooling of NA land surface induced by enhancement of $N A$ rainfall}

NASR is negatively correlated with NA land surface temperature (Figs. 4 and 5a). The correlation between the detrended NASR and land surface temperature is -0.72 , which is significant at the 0.05 level. Furthermore, their linear trends are opposite: NA land surface temperature decreases significantly, but NA rainfall increases significantly (Fig. 4). This indicates that heavier precipitation is usually accompanied by a cooler land surface temperature over NA. On the other hand, a cooler surface temperature is known to weaken or suppress the local ascending motion and precipitation. As a result, the increase of NASR is unlikely induced by NA land surface cooling, but rather that NA land surface cooling is induced by increasing NASR.

The cooling of the NA land surface induced by increasing NASR is well supported by the strong positive correlation between NASR and TCDC (Fig. 5b), and SLHNF (Fig. 5c) over the NA continent. The positive correlation means more rainfall is always accompanied by more cloudiness (Fig. 5b) and more surface evaporation (Fig. 5c) over NA. The more cloud cover and surface 

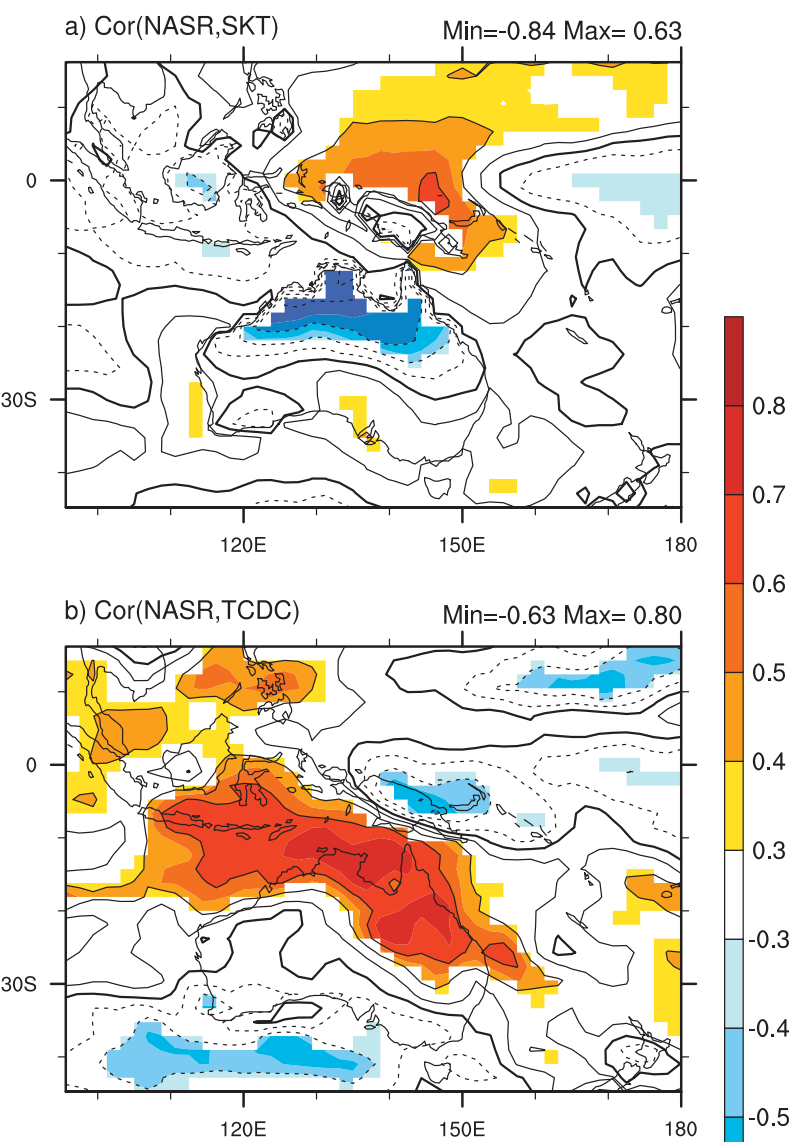

0.6

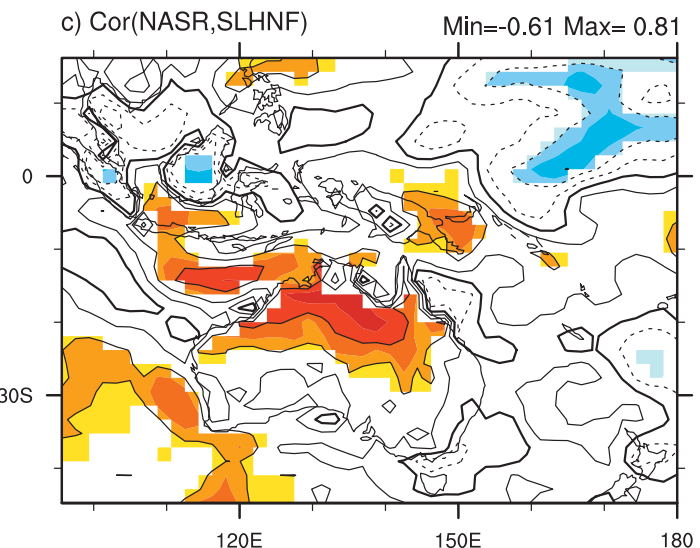

FIG. 5. Correlation map between the NASR and (a) SKT, (b) TCDC, and (c) SLHNF in austral summer during 1979-2010. Contour interval is 0.2 ; thin black (thin dashed) contours denote positive (negative) values, and the bold black contour is zero. Areas significant at the 0.10 level are color shaded. Effective degrees of freedom (not shown) are estimated according to Eq. (2).

more evaporation over the NA land area, the less incoming solar shortwave radiation reaches the land surface as well as more heat removed from the land surface through more evaporation, the cooler of NA land a) Cor(NASR,SST)

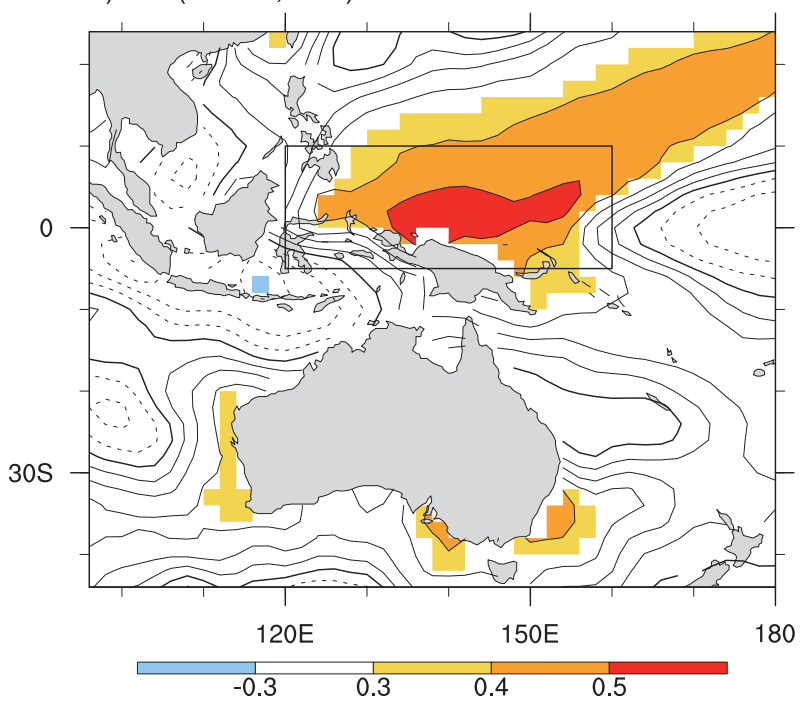

b) $\operatorname{Reg}(T W P I, R a i n)$

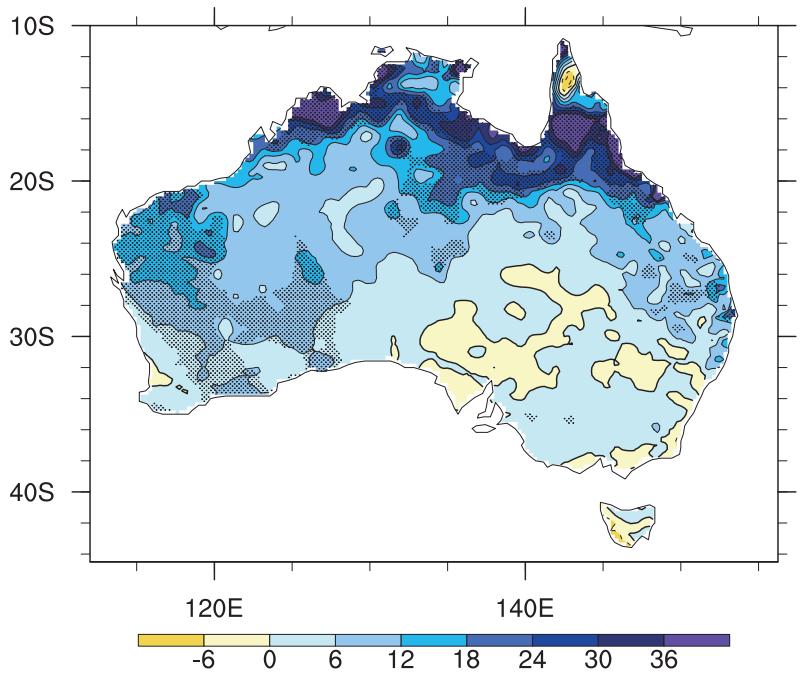

FIG. 6. Map of (a) correlation between the NASR and SST and (b) linear regression of Australian rainfall ( $\mathrm{mm}$ ) onto the normalized TWPI in austral summer during 1979-2010. Contour interval is 0.1 in (a) and 6 in (b), thin black (thin dashed) contours denote positive (negative) values and the bold black contour is zero. Areas significant at the 0.10 level are color shaded in (a) and stippled with little black dots in (b). Effective degrees of freedom (not shown) are estimated according to Eq. (2). Rectangular box in (a) marks the TWP area $\left(5^{\circ} \mathrm{S}-10^{\circ} \mathrm{N}, 120^{\circ}-160^{\circ} \mathrm{E}\right)$; average SSTA over this box is defined as the TWPI.

surface. Therefore, the recent cooling of NA surface temperature is actually a negative feedback to the enhancement of NASR. Similarly, negative feedbacks of surface temperature to rainfall in other regions have also been noted in previous studies (e.g., CornejoGarrido and Stone, 1977; Webster et al. 1996; Hendon et al. 2007). 
TABLE 1. Correlations between NASR and AUSMI (Li and Zeng 2000, 2002, 2003), Niño-3.4, TWPI. Data in austral summer from 1979 to 2010. Correlations of each variable with year are also listed. Partial correlations between rainfall and year, after the removal of signals of the variable at the head of each column, are also listed. Correlations significant at the 0.05 level are in bold; The quantities $N_{\text {eff }}$ and $N_{\text {edof }}$ are reestimated.

\begin{tabular}{llcc}
\hline \hline & AUSMI & Niño-3.4 & \multicolumn{1}{c}{ TWPI } \\
\hline Correlation with rainfall & $\mathbf{0 . 5 9}\left(N_{\text {edof }}=30\right)$ & $-\mathbf{0 . 3 7}\left(N_{\text {edof }}=30\right)$ & $\mathbf{0 . 4 7}\left(N_{\text {edof }}=20\right)$ \\
Correlation with year & $0.03\left(N_{\text {eff }}=32\right)$ & $-0.13\left(N_{\text {eff }}=32\right)$ & $\mathbf{0 . 6 7}\left(N_{\text {eff }}=11\right)$ \\
Partial correlation & $\mathbf{0 . 5 3}\left(N_{\text {eff }}=32\right)$ & $\mathbf{0 . 4 3}\left(N_{\text {eff }}=32\right)$ & $0.15\left(N_{\text {eff }}=32\right)$ \\
\hline
\end{tabular}

\section{Variability of NA summer rainfall and connections with neighboring SST}

\section{a. Connections between NA rainfall and SST}

Figure 6a shows the correlation between NASR and SST over much of the TWP and wider Australian region. There are significant positive correlations centered in the TWP region, indicating that higher NA rainfall is usually associated with warmer SST over the TWP in recent decades, and vice versa. To see the influence of TWP, we investigated the correlation between the TWP index and summer rainfall over the Australian continent. The correlation coefficient between the time series of TWPI and NASRI is 0.47 , significant at the 0.05 level $\left(N_{\text {edof }}=20\right.$, Table 1$)$. Regressing Australian summer rainfall onto TPWI (Fig. 6b), we can see significant regression patterns are centered over NA, central Australia, and inland southwest Western Australia, suggesting the rainfall pattern associated with TWPI is very similar to the recent NA rainfall trend pattern (Fig. 1a).

Tropical SST over the TWP is not only significantly correlated with NA rainfall, but also has shown an upward trend in recent decades. As shown in Fig. 7, a general increase of warming SST has been observed around the Australian continent since the late 1970s. In particular, the significant warming is mainly observed at the TWP region, where it is directly to the north of NA (Fig. 8a). TWPI has a strong correlation (0.66) with year, which is significant at the 0.05 level $\left(N_{\text {edof }}=9\right.$, Table 1$)$, indicating a significantly upward trend in recent decades.

As the TWP is part of the ENSO operating region and ENSO is significantly correlated with NASR (correlation coefficient is -0.37 , significant at the 0.05 level for $N_{\text {edof }}=30$ ), an intuitive question is whether ENSO has an influence on the NA rainfall trend. Since there is no significant trend in the Niño-3.4 index (Fig. 8b), it

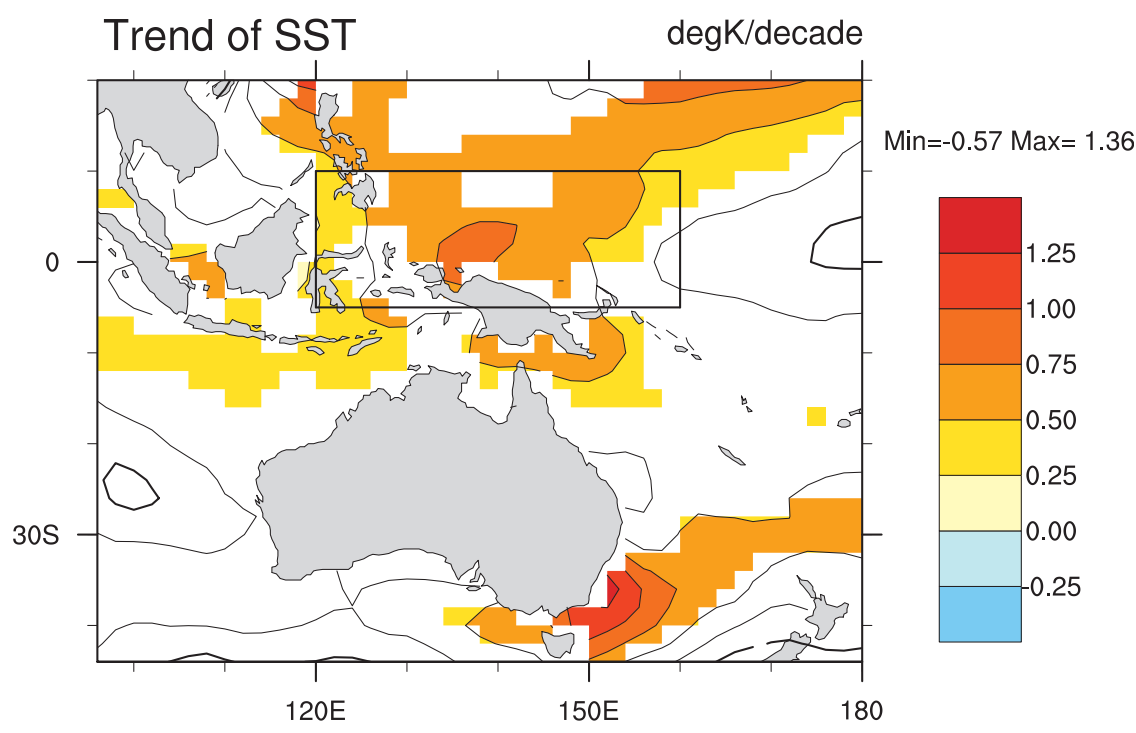

FIG. 7. Linear trend of austral summer SST $\left(\mathrm{K} \mathrm{decade}^{-1}\right)$ during 1979-2010. Contour interval is $0.3 \mathrm{~K} \mathrm{decade}{ }^{-1}$. Thin black (thin dashed) contours denote positive (negative) values, and the bold black contour is zero. Areas with significant trends at the 0.05 level are color shaded. Effective sample sizes are reestimated (not shown) according to Eq. (1). Rectangular box marks the TWP area $\left(5^{\circ} \mathrm{S}-10^{\circ} \mathrm{N}, 120^{\circ}-160^{\circ} \mathrm{E}\right)$. 
a) TWPI $(R Y=0.66)$

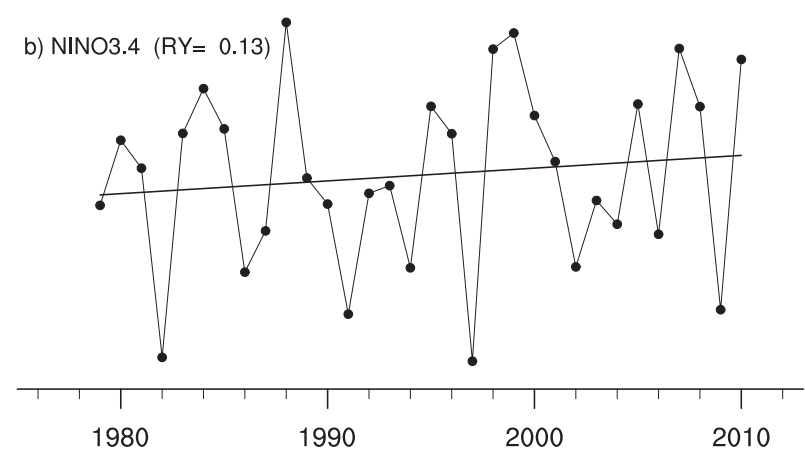

FIG. 8. Normalized time series (curves with black circles) of (a) the TWPI and (b) the Niño-3.4, and their respective linear trends (black straight line) in austral summer during 1979-2010. Niño-3.4 is reversed for the comparison. Effective sample sizes (not shown) are reestimated according to Eq. (1). Shown are $N_{\text {eff }}=11$ for TWPI and $N_{\text {eff }}=32$ for Niño-3.4. The RY is the correlation between the index and year and indicates a linear trend significant at the 0.05 level in TWPI if its value $\geq \pm 0.60$.

implies that the increase of NASR is not driven by ENSO. This result is consistent with an earlier study by Shi et al. (2008) that suggested that ENSO does not contribute to the increase in NWA (a part of NA) summer rainfall during the second half of the twentieth century. Similarly, Simmonds et al. (1996) found that ENSO appears to play a small role in China summer rainfall, but a key influence is the TWP.

We have investigated the influence of ENSO Modoki on NASR using a correlation map between the ENSO Modoki and rainfall over the Australian continent in DJF (figure not shown). It is found that there are no significant correlations between ENSO Modoki and NASR in DJF during the 1979-2010 period. Additionally, there is no significant trend in the ENSO Modoki index. Hence, ENSO Modoki cannot influence the increase of NASR. This result is consistent with a previous study showing that Modoki-like SST anomalies produce the maximum rainfall response over northern and northwestern Australia during March-May (MAM) rather than during December-February (Taschetto and England 2009b).

Since ENSO and ENSO Modoki events are not responsible for the increase of NASR, given observed strong warming in TWP region, we now focus on its influence on the recent increase of NASR.

\section{b. Tropical western Pacific warming and NA rainfall trend}

Following Nicholls (2010) and Feng et al. (2010), a partial correlation method is used to investigate the contribution of increasing TWP SST to the wetting trend of NA averaged summer rainfall. The correlation between NASRI and year is 0.45 , which is significant at the 0.05 level after taking into account the autocorrelation in the data $\left(N_{\text {edof }}=30\right)$. This result suggests a significant increasing trend in NASRI. After linearly removing the influence of TWPI, the partial correlation between NASRI and year drops to 0.15, which is not significant (Table 1), indicating that most of the increase in rainfall is associated with the warming trend in the TWP. In contrast, after removing the influence of AUSMI/Niño-3.4, the partial correlation between NASR and year has only slightly dropped, from 0.45 to 0.43 , which remains significant at the 0.05 level (Table 1 ). This is consistent with the aforementioned results that the increase in rainfall is not associated with AUSM and with Niño-3.4. Furthermore, Fig. 9 shows that the residuals of NASRI after removal of the rainfall predicted using TWPI exhibit almost no trend, but the residuals of the rainfall time series after removal of the rainfall predicted using the AUSMI and Niño-3.4 still exhibit significant linear trends. This result is another demonstration that the increase of NASR is associated with the TWP, but not AUSM and Niño-3.4.

Figure 10a shows a correlation map between Australian summer rainfall and year. It is evident that significant positive correlation patterns are mainly located in NA, suggesting a wetting trend exists in NA. After removing the influence of AUSMI (Fig. 10b) and Niño-3.4 (Fig. 10c), the areas with significant correlations almost remain the same. However, these significant correlations disappeared after the removal of the TWPI signal (Fig. 10d). Therefore, the warming SST centered in the TWP may be linked to the increase of NASR over last three decades.

To assess how much of the recent NA rainfall wetting trend is associated with warming SST in the TWP, yearto-year differences were calculated for time series of NASRI and the TWPI, and then linear regression and correlation were calculated between them (Nicholls 2010). The linear regression between the year-to-year differences of NASR and TWPI then allow the estimation of the rainfall trend that should be expected from the trend in TWP through the relationship between NASR and the TWPI. Accordingly, a sensitivity of NASR to TWPI is defined as the slope of the TWPI in the fitted 


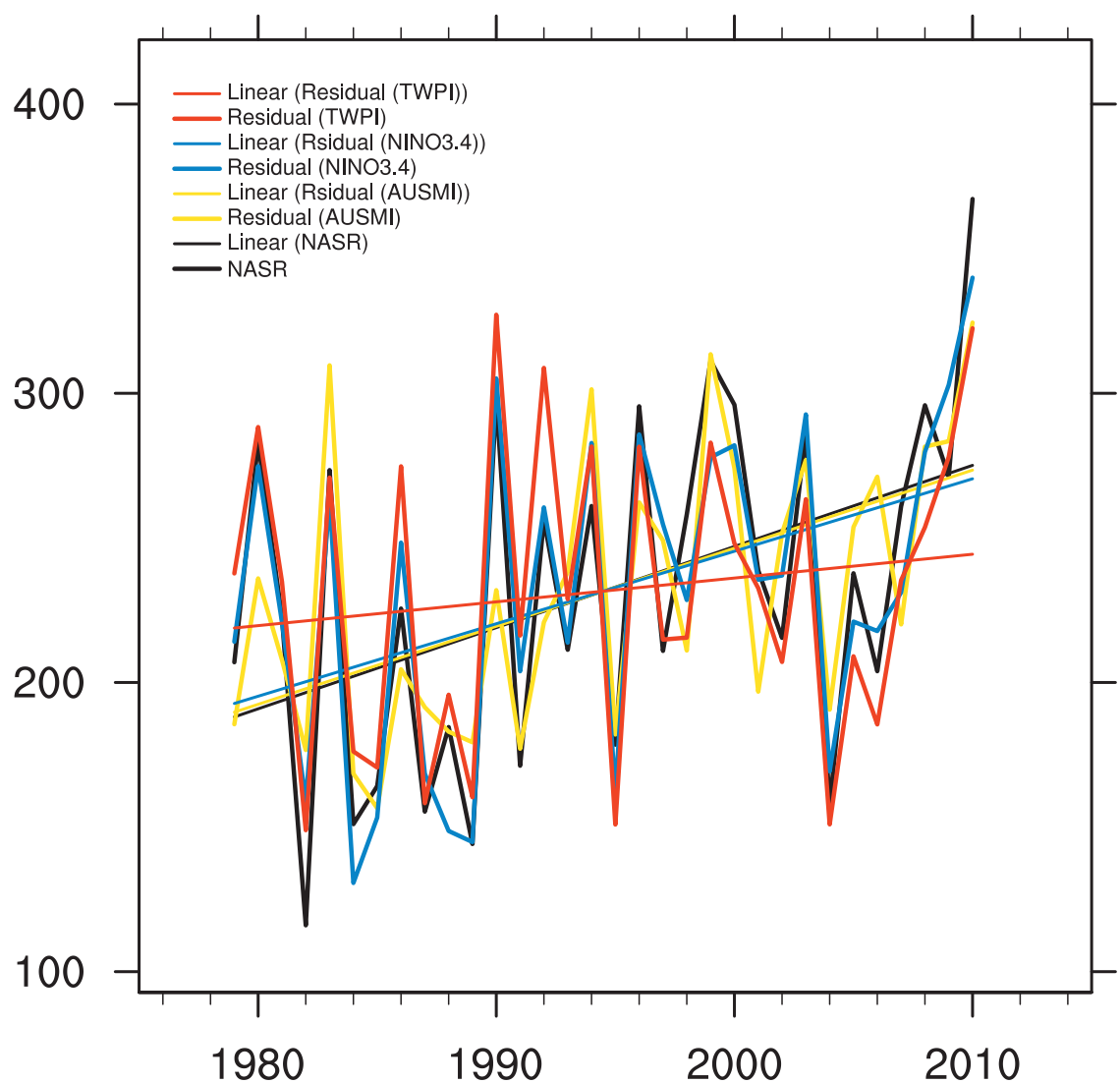

FIG. 9. Time series (1979-2010) of austral summer NASR and time series of residual NASR from rainfall predicted with linear regressions using TWPI, Niño-3.4, and AUSMI as a predictor. Linear trends are shown for all variables.

linear regression model for the relationship between year-to-year differences of NASR and TWPI. Thus, assuming that the relationship derived from the year-toyear differences operates on multidecadal time scales, the NASR trend induced by the TWP can be estimated as the product of the sensitivity and the trend of the TWPI. Hence, the ratio of the TWP-induced trend value to the observed NASR trend value $\left(82 \mathrm{~mm} \mathrm{decade}^{-1}\right)$ measures the contribution of TWPI to the NWR trend during the period from 1979 to 2010. Similarly, the contributions of other climate modes (e.g., AUSMI and Niño-3.4) to the NASR trend were calculated for a comparison and their values were listed in Table 2. We can see from Table 2 that the NA wetting trend induced by AUSMI, Niño-3.4, and TWPI are 3.1, 9.8, and $43.39 \mathrm{~mm} \mathrm{decade}^{-1}$, respectively. In other words, warming SSTs of the TWP can explain $52.7 \%$ of the observed increasing trend $\left(82 \mathrm{~mm} \mathrm{decade}^{-1}\right)$ in NASR, but AUSM and ENSO can only explain $3.8 \%$ and $11.2 \%$, respectively. Therefore, the warming SST in the TWP has contributed more than $50 \%$ of the recent NA wetting trend in the 1979-2010 period.

\section{Dynamical effects of the increasing SST in the TWP on NA rainfall}

In this section, we investigate the dynamical effects of warming SST in the TWP on NA summer rainfall and atmospheric circulation via the diabatic heating.

\section{a. Thermal driving of $N A$ rainfall increase}

Sensible heat represents the temperature difference between the sea-land surface and the atmosphere above it. It is used as an indicator of the heating effect of the sea-land surface on the atmosphere. As shown in Fig. 11a, significant positive correlations between NASR and SSHNF mainly occur over the TWP and the southern Indian Ocean, while significant negative correlations mainly exists over the land area of NA.

As a result, significant positive correlations over the TWP indicate that the increasing rainfall in NA is associated with the atmosphere being heated over the TWP. On the other hand, because the significant warming of SST in the TWP has been observed in recent years, it is expected that there is a direct heating effect on the atmosphere 
a)

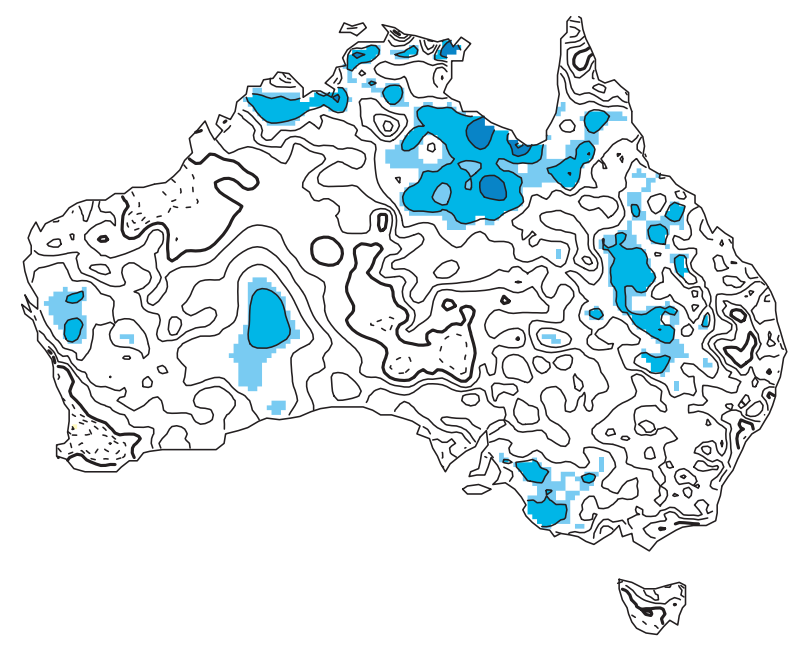

c)

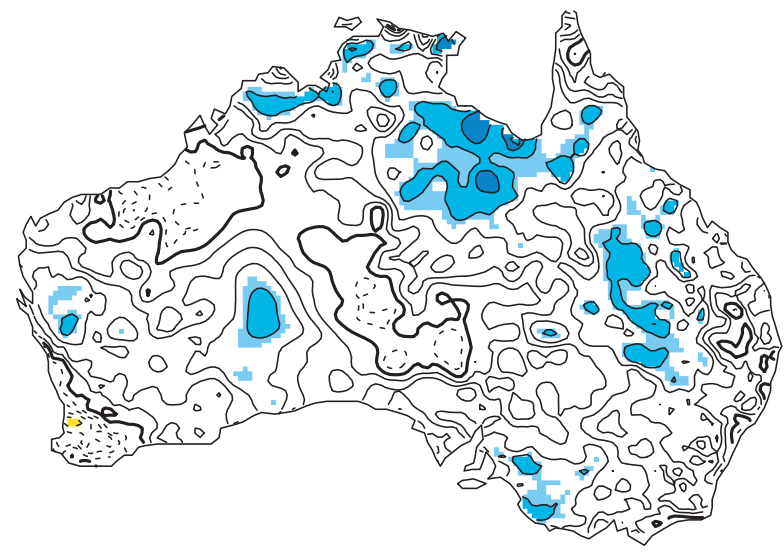

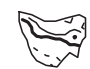

b)

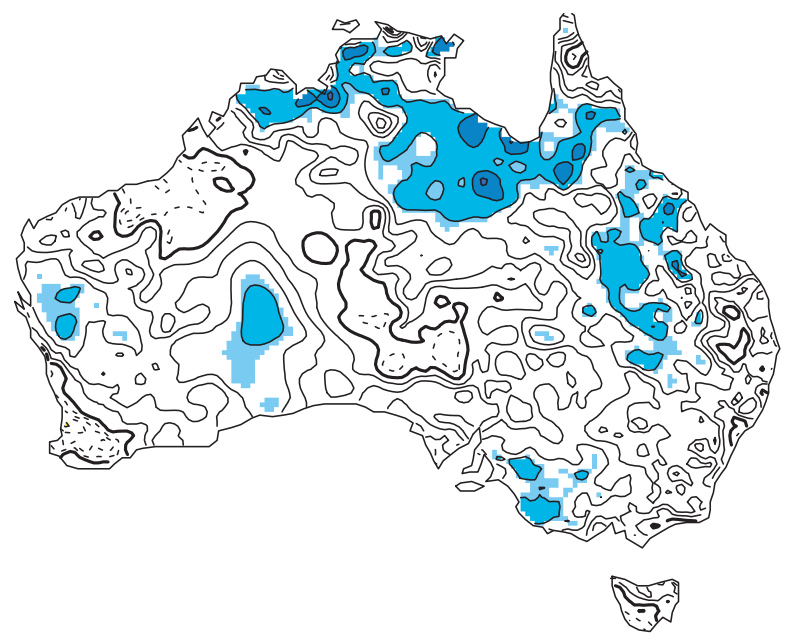

d)

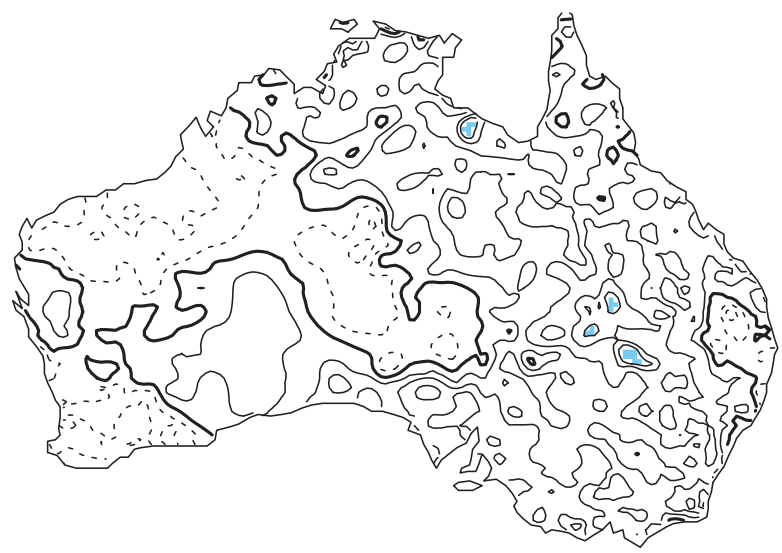

$\ddot{2}$



FIG. 10. Correlation between the year and (a) the Australian NA summer rainfall, (b) the residual Australian NA summer rainfall after the removal of AUSMI, (c) the residual Australian NA summer rainfall after the removal of Niño-3.4, and (d) the residual Australian NA summer rainfall after the removal of TWPI during 1979-2010. Areas with significant trends at the 0.05 level are color shaded. Effective sample sizes (not shown) are reestimated according to Eq. (1).

over the TWP. Accordingly, it is natural to hypothesize that the intensified diabatic heating induced by warming SST in the TWP may instigate a Gill-type response (Gill 1980) in the atmosphere circulation, which increases rainfall in NA. Indeed, a significant Gill-type cyclonic structure is observed in SLP and $850-\mathrm{hPa}$ wind fields (Fig. 11b). This Gill-type cyclone is located to the south of the TWP, covering the whole NA land area, the adjacent Timor Sea, and Wharton Basin. It causes anomalous low pressure and moisture convergence over the NA land area, and this anomalous low pressure and moisture convergence is resulting in a rainfall increase over NA (Simmonds et al. 1992). Moreover, the Gill-type cyclone brings not only anomalous moist sea breezes to the northeast coast of NA, but also dry land breezes to the southeast of NA, causing the rainfall increase over the northeast coast of NA to be stronger than that over the southeast coast of NA (see Figs. 1a and 2a). So, the thermal heating of the TWP has caused the increase of NA rainfall in the recent three decades. 
TABLE 2. Sensitivity of NASR associated with AUSMI (Li and Zeng 2000, 2002, 2003), Niño-3.4, and TWPI, as well as trends of these indexes and their induced NA rainfall trends in austral summer over 1979-2010. Sensitivity is estimated by applying the regression (slope) between year-to-year changes (removing the linear trend) in NASR and the index; the induced NASR trend is the product of the sensitivity and the index trend in 32 years over 1979-2010. Correlations or regressions significant at the 0.05 level are in bold; The quantities $N_{\text {eff }}$ and $N_{\text {edof }}$ are reestimated. Therefore, the TWPI can account for $52.7 \%$ of the trend in NASR.

\begin{tabular}{lccr}
\hline & AUSMI & Niño-3.4 & TWPI \\
\hline $\begin{array}{l}\text { Correlation (year-to-year } \\
\quad \text { differenced data) }\end{array}$ & $\mathbf{0 . 6 4}$ & $\mathbf{- 0 . 4 5}$ & 0.25 \\
Sensitivity (mm unit $^{-1}$ ) & $\mathbf{8 6 . 9 7}$ & $\mathbf{- 2 2 . 2 9}$ & 81.57 \\
$\begin{array}{l}\text { Trend (unit decade } \\
\text { Ind }\end{array}$ & 0.04 & -0.44 & $\mathbf{0 . 5 3}$ \\
$\begin{array}{l}\text { Induced NASR trend } \\
\quad\left(\text { mm decade }^{-1} \text { ) }\right.\end{array}$ & 3.1 & 9.8 & 43.39 \\
$\begin{array}{l}\text { Contribution (\%) to the NASR } \\
\quad \text { trend (82 } \text { mm decade }^{-1} \text { ) }\end{array}$ & 3.8 & 11.2 & 52.7 \\
\hline
\end{tabular}

In response to the rainfall increase in NA, the surface temperature of NA has decreased, and it leads to the loss of the SHNF in the atmosphere over NA (Fig. 11a). As to the significant positive correlations between NASR and the SHNF in the southern Indian Ocean (Fig. 11a), it is mainly attributed to a response to the anomalous southeasterly cold advection brought by the Gill-type cyclone. Therefore, the increased rainfall in NA results from an anomalous cyclone due to a Gill-type response to the warming SST in the TWP; and this increased rainfall in turn causes the cooling of the NA land surface.

\section{b. Modeling rainfall response to the TWP warming}

To further verify the above-mentioned mechanism that the increased rainfall in NA is driven by warming SST in the TWP, SST forcing experiments were conducted using the SAMIL-R42L9 model. In the control simulation, perpetual mean January climate has been imposed, including the solar height angle, the length of day, and SST. The main features of the austral summer are reproduced successfully in the control experiment (e.g., Wu et al. 2003, 2012). In the sensitivity experiment, the constant SST anomalies (SSTAs) were added to the climate mean January SST, and used as the lower boundary forcing. The added SSTAs are located over the tropical ocean region $\left(20^{\circ} \mathrm{S}-10^{\circ} \mathrm{N}, 110^{\circ}-160^{\circ} \mathrm{E}\right)$, where is centered on the TWP. To make the simulated results more comparable with observational results, we use the observed linear trend for austral summer during 1979-2010 as the added SSTA forcing, except these values are doubled (Fig. 12a). The spinup time in these experiments is very short being just about six years. We use if the value of the energy budget at the top of a)

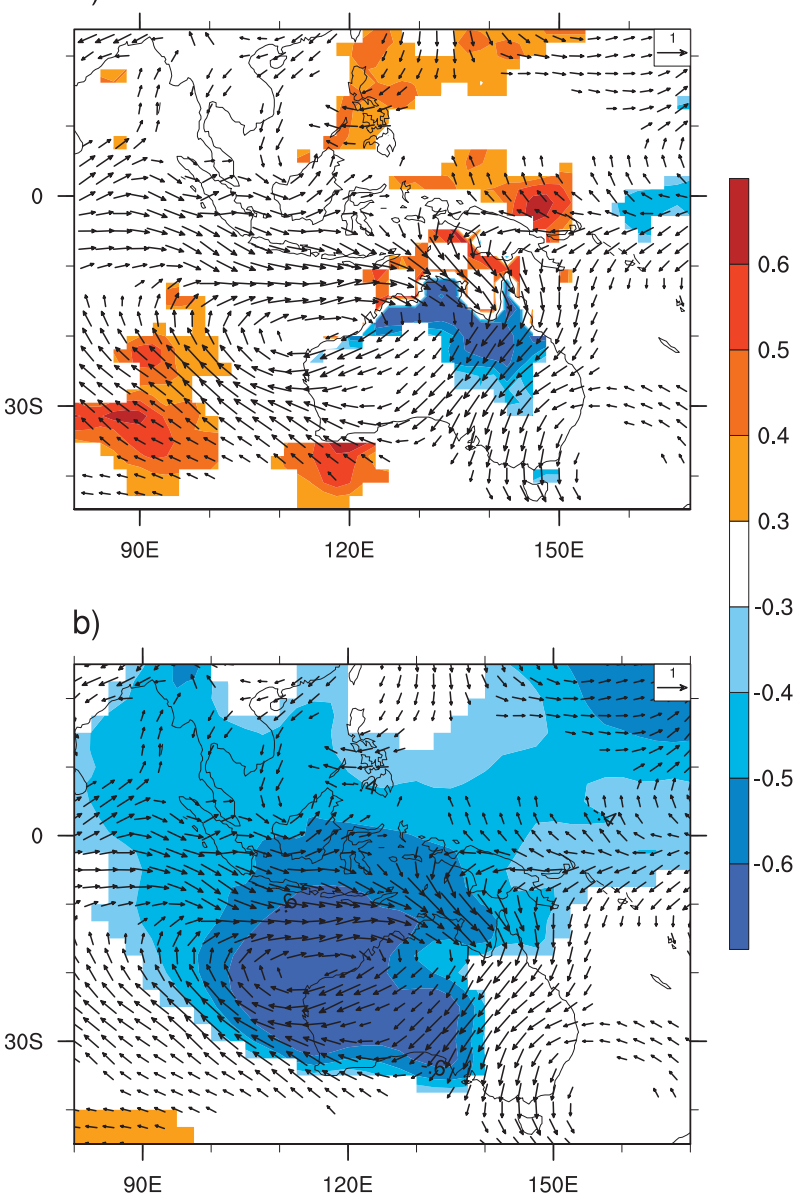

FIG. 11. Maps showing the correlation between the NASR and wind vectors $\left(\mathrm{m} \mathrm{s}^{-1}\right)$ at $850 \mathrm{hPa}$ and the correlation between the NASR and (a) the SHNF at the surface and (b) the SLP in austral summer during 1979-2010. The vector here is a vector of correlations significant above the 0.10 level whose two components are the correlation coefficients between the NASR and anomalously zonal wind and between the NASR and anomalously meridional wind velocity. Areas significant at the 0.10 level are color shaded. Effective degrees of freedom (not shown) are estimated according to Eq. (2).

the atmosphere reaches its quasi-asymptotic value as the criterion to judge whether the model is integrated to the equilibrated state. This method follows Simmonds (1985). Differences between the enhanced SST and control experiments are then computed from data covering a $30-\mathrm{yr}$ period.

Figure 12 shows that the increased rainfall in NA driven by the warming SST in the TWP through a Gilltype cyclone response can be well simulated in the conducted SST forcing experiments. Specifically, in response to SST warming of the TWP, anomalous low pressure and $850-\mathrm{hPa}$ winds due to the Gill-type cyclone form in the experiments are similar to the observed ones (Figs. 11b versus 12b). As such, the intensified 

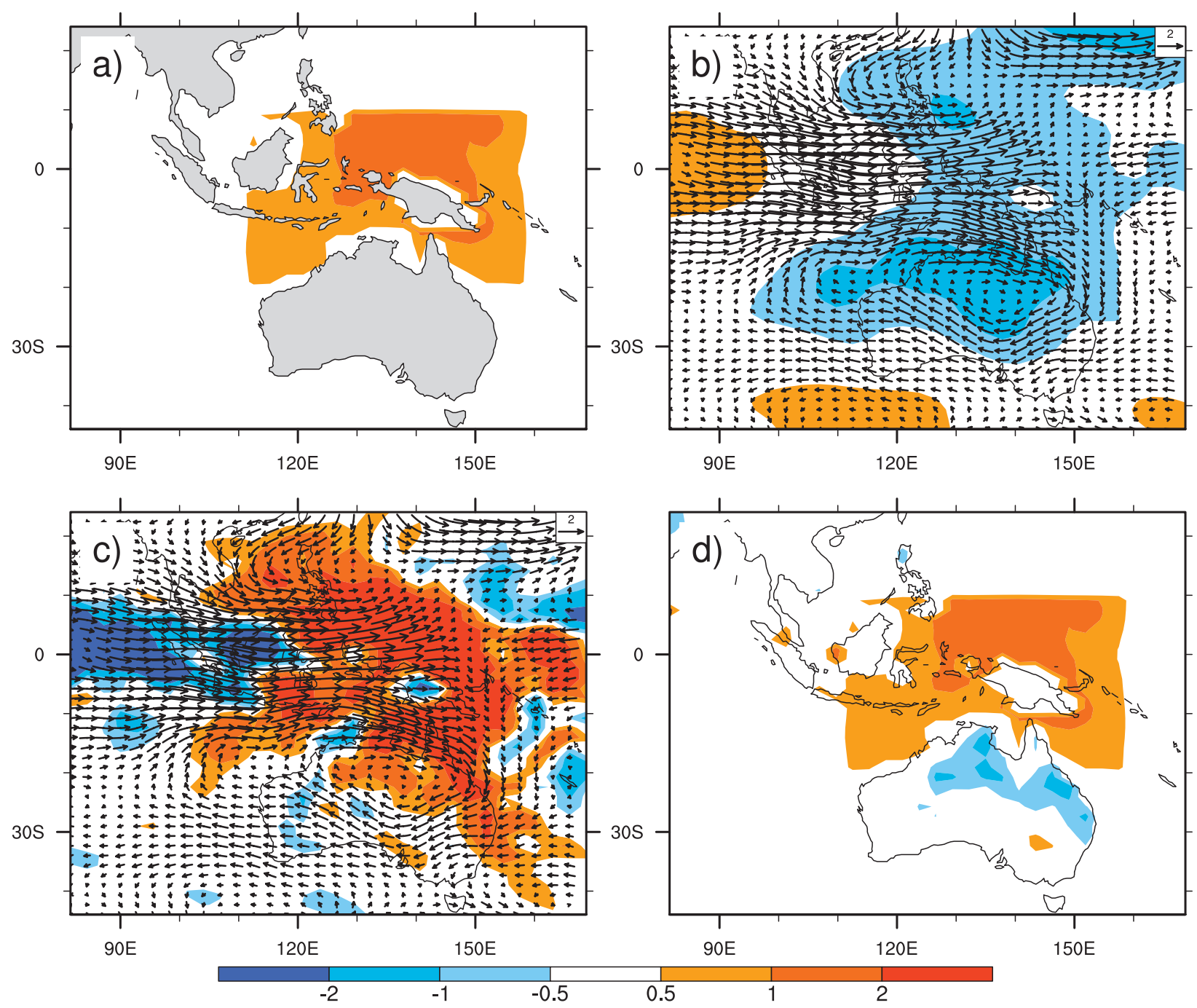

FIG. 12. Difference between the enhanced SST and control simulations of austral summer (DJF): (a) SST (K), (b) surface pressure (hPa) and $850-\mathrm{hPa}$ wind vector $\left(\mathrm{m} \mathrm{s}^{-1}\right),(\mathrm{c})$ rainfall $\left(\mathrm{mm} \mathrm{day}^{-1}\right)$ and $850-\mathrm{hPa}$ wind vector $\left(\mathrm{m} \mathrm{s}^{-1}\right)$, and (d) surface temperature $(\mathrm{K})$.

NA rainfall pattern (Fig. 12c) is very similar to the observed wetting trend pattern illustrated in Fig. 2a. Moreover, a lower NA land surface temperature anomaly also occurs as a response to the enhanced NA rainfall (Fig. 12d).

In summary, as shown in the schematic mechanism in Fig. 13, direct thermal forcing instigated by increasing SST over the TWP gives rise to an anomalous Gill-type cyclone centered around NA, leading to anomalously high rainfall, cloudiness, and more surface evaporation to NA. The increased rainfall in turn induces the land surface cooling in NA.

\section{Summary and discussion}

In this study, the recent rainfall trend over NA has been investigated. It is found that a significant wetting trend has dominated over the whole NA during the austral summer in the past three decades, 1979-2010. The increase in rainfall over NEA is slightly greater than that over NWA. The observed rainfall in DJF for 1979-2010 was projected onto three modes of rainfall variability. Only the leading mode of NA rainfall shows a dominant increasing pattern over NA, and its principal component (PC) series is highly correlated (0.94) with the average rainfall over NA. The dominated increasing trend in NA rainfall is therefore associated with the leading mode of NA rainfall variability since 1979.

We have investigated the influence of some wellknown climate drivers (including AUSM, ENSO, and EMSO Modoki) on the influence of NASR. Although AUSM is connected closely with the interannual variability of NASR, it cannot be the driver of the NA 


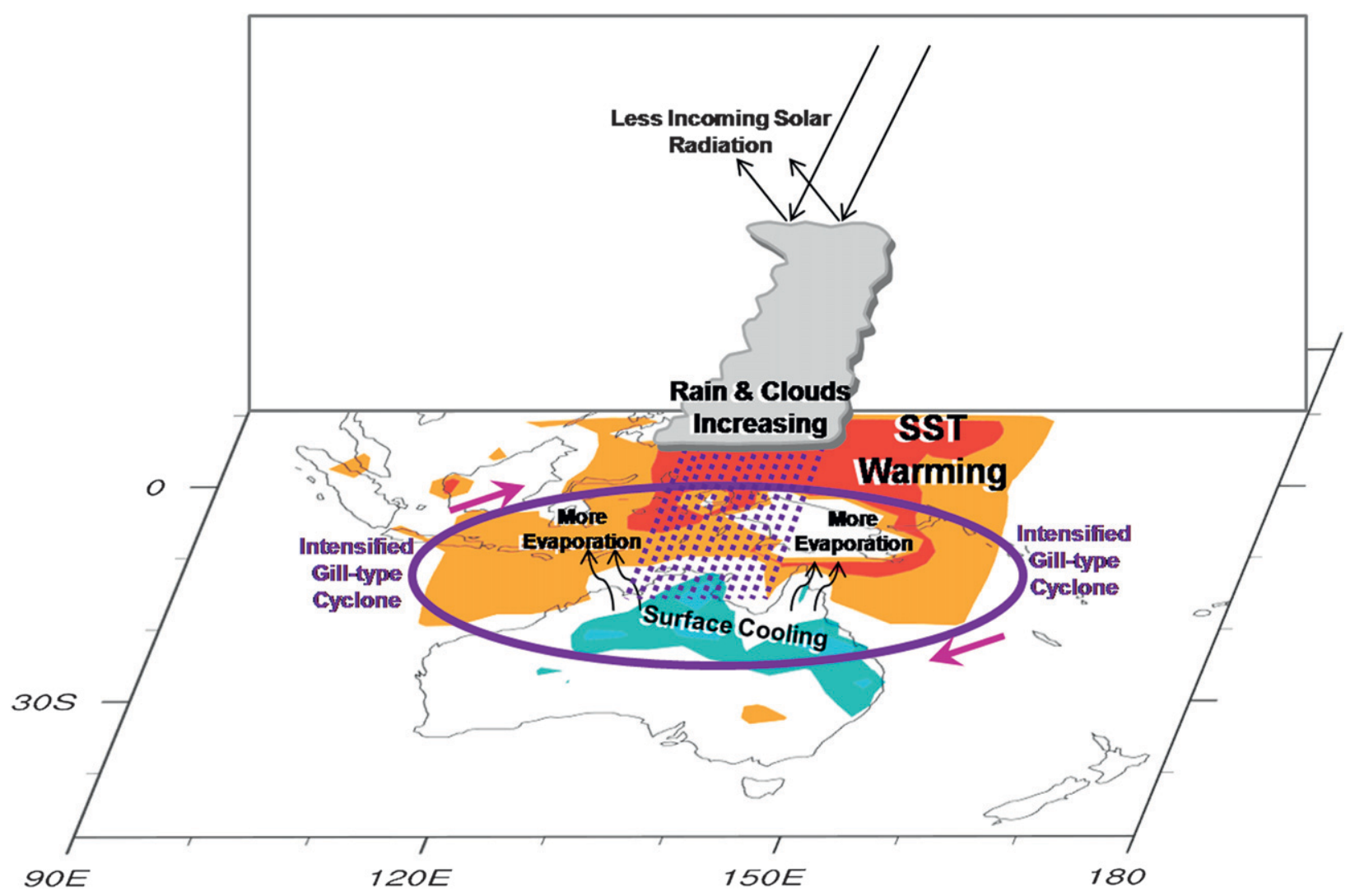

FIG. 13. Schematic of the increase of the NA summer rainfall following the warming of the TWP in recent decades.

rainfall trend because there is no trend in AUSM. Similarly, ENSO cannot explain the increase of NA rainfall because of its lack of a linear trend. Also, ENSO Modoki is not attributed to the increase of NASR because it has no significant link to NASR in austral summer. In construct, we find that the increasing SST in the TWP plays a predominant role in the rainfall increase in NA; that is, the increase SST in the TWP drives the formation of an anomalous Gill-type cyclone, which results in anomalous low SLP over NA and more rainfall, cloud, and surface evaporation over the entire NA, and so cools down the NA land surface (Fig. 13). Results obtained from numerical experiments also demonstrate that the increased tropical SST centered on the TWP can cool down the NA land surface through intensifying the rainfall over NA. Therefore, the increasing rainfall and land surface cooling in NA are a result of an anomalous cyclone due to a Gill-type response to the warming SST in the TWP.

Our results reported here suggest that the NA summer rainfall trend has been dominated by a wetting trend after 1979, which is different from the well-known dipole trend during the second half of the twentieth century. Moreover, the dynamics driving the wetting trend in NA after 1979 are different from those driving the strong zonal-dipole trend pattern in NA summer rainfall known as rainfall increased in NWA but decreased in NEA during the second half of the twentieth century (e.g., Smith 2004; Shi et al. 2008; Taschetto and England 2009a; Feng et al. 2013). Previous studies have shown that the observed positive trend in rainfall over NWA in DJF since 1950s is closely related to the lowertropospheric circulation and SST changes in the south Indian Ocean (e.g., Shi et al. 2008; Feng et al. 2013), while the decrease in NEA rainfall during 1948-2007 could be attributed to variability of the AUSM because of the continuous warming trend of SST in the Wharton Basin (J. Li et al. 2012). The dynamics of driving the wetting trend in NA results from an anomalous cyclone due to a Gill-type response to the warming SST in the TWP after 1979.

To understand the changes of the dynamics driving trends in summer rainfall in the subregions (NWA and NWA) of NA before and after 1979, the correlations of the average rainfall over NEA and NWA with SST were calculated for the pre-1979 period (1948-79) and after the 1979 period (1979-2010) (Fig. 14). Figure 14a shows that the NWA rainfall is significantly related to SST 
a) $\operatorname{Cor}(N W A R, S S T)$

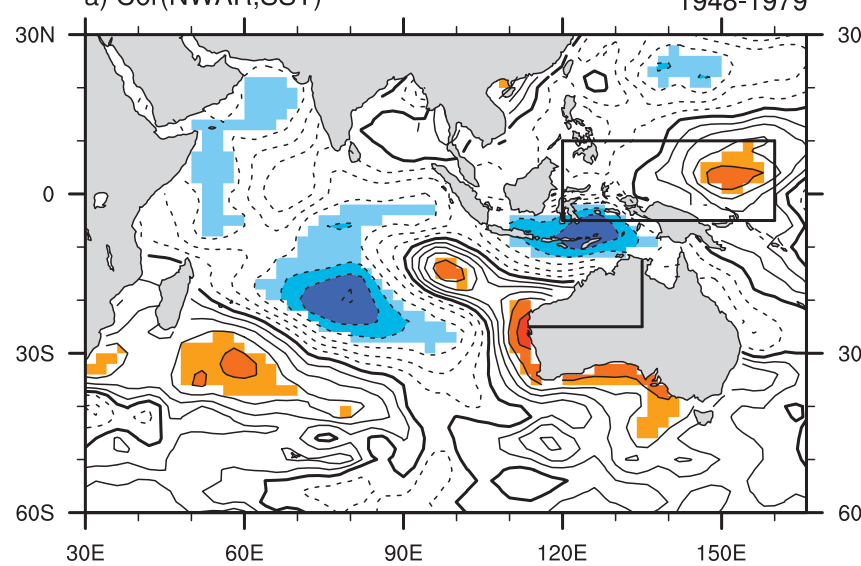

c) $\operatorname{Cor}(\mathrm{NEAR}, \mathrm{SST})$

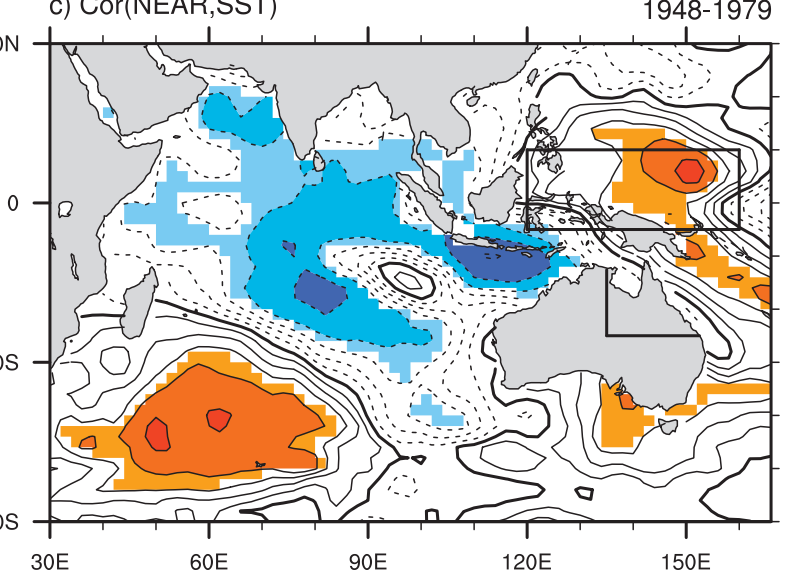

b) $\operatorname{Cor}(N W A R, S S T)$

1979-2010

d) $\operatorname{Cor}(N E A R, S S T)$

1979-2010

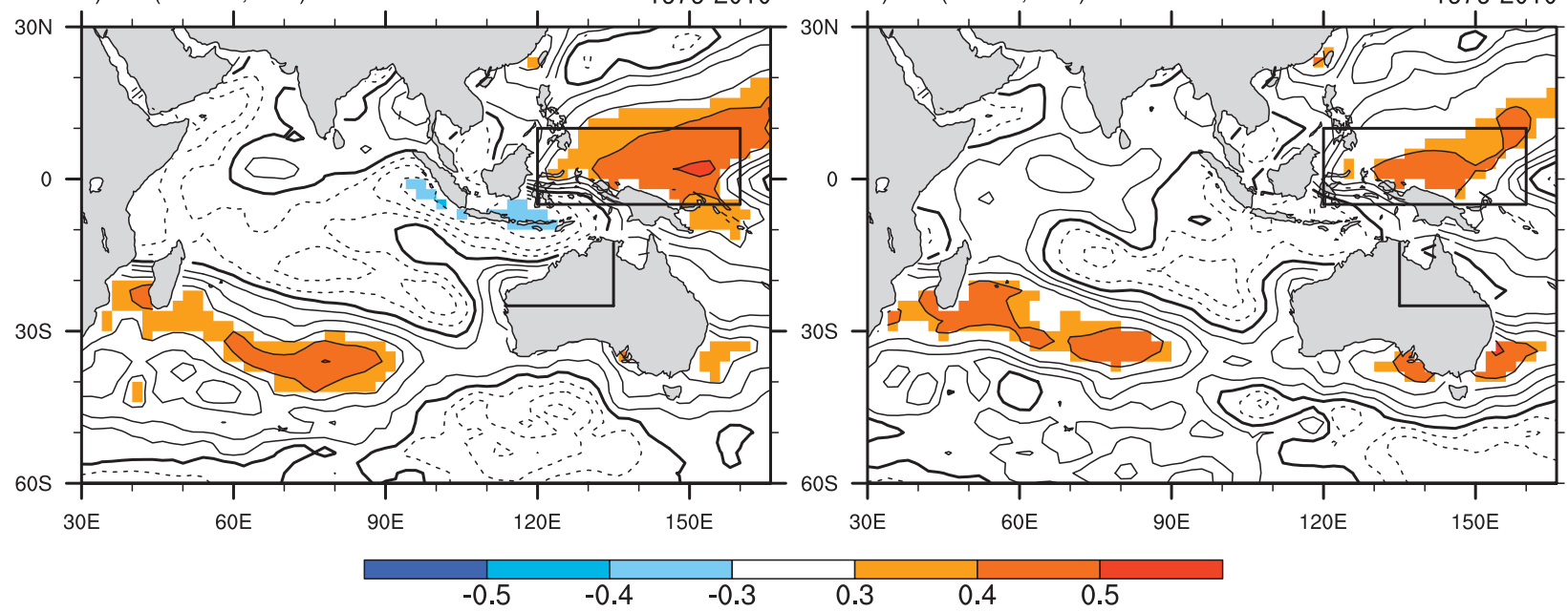

FIG. 14. Correlation maps between the Australian summer rainfall and SST. (a) NWA $\left(25^{\circ}-10^{\circ} \mathrm{S}, 112^{\circ}-135^{\circ} \mathrm{E}\right.$, denoted as solid lines) averaged rainfall with SST during 1948-1979 and (b) during 1979-2010; (c) NEA ( $25^{\circ}-10^{\circ} \mathrm{S}, 135^{\circ}-155^{\circ} \mathrm{E}$, denoted as solid lines) averaged rainfall with the SST during 1948-1979 and (d) during 1979-2010. Contour interval is 0.1; thin black (thin dashed) contours denote positive (negative) values, and the bold black contours denote zero. Areas significant at the 0.05 level are color shaded. Effective degrees of freedom (not shown) are estimated according to Eq. (2). Rectangular box marks the TWP area $\left(5^{\circ} \mathrm{S}-10^{\circ} \mathrm{N}, 120^{\circ}-160^{\circ} \mathrm{E}\right)$.

changes in the south Indian Ocean before 1979. This agrees well with the dynamic that the enhancement of the zonal gradient of SST over the south Indian Ocean toward the Western Australian coast (Fig. 11c in Shi et al. 2008). After 1979, this correlation between NWA rainfall and SST in the south Indian Ocean disappears, while the positive correlation between NWA rainfall and SST in the TWP becomes a dominant signal (Fig. 14b). NEA rainfall changes similarly. Before 1979, NEA rainfall is significantly related to the variability of SST in the Wharton Basin, located in the northeast Indian Ocean, as suggested by J. Li et al. (2012). After 1979, this connection is weakened, and TWP SST then controls the NEA rainfall variability. These comparisons demostrate that the SST changes in the TWP have replaced the SST in the south and northeast Indian Ocean as the controlling factor for both NWA and NEA summer rainfall after the late 1970s.

In summary, the increase in SST in the TWP can be considered as a main driver of the long-term wetting trend of northern Australia summer rainfall during the latest three decades (1979-2010). The dominant wetting trend in NA after 1979 suggests that the drought and wet conditions over northern Australia may experience multidecadal variations. This also raises some interesting questions, Why did the NA rainfall change dramatically around 1979? How will the TWP SST and NA rainfall change in the future? Further work will be required to address these questions and the underlying mechanisms. 
Acknowledgments. We thank Prof. Jianping Li, Dr. Kwok Wai Lau, Dr. Aloke Phatak, and two anonymous reviewers, whose comments greatly improved the paper. This work was carried out by Jingjing $\mathrm{Yu}$ and Xiaofeng Li during their CSIRO visit in 2011-2012, jointly supported by a National Basic Research Program of China (Grant 2010CB950400), the National Natural Science Foundations of China (Grants 40905040 and 41030961), and a CSIRO-Chinese Ministry of Education visiting scholar fund; the Indian Ocean Climate Initiative; and CSIRO Climate Adaptation Flagship.

\section{REFERENCES}

Ashok, K., S. K. Behera, S. A. Rao, H. Weng, and T. Yamagata, 2007: El Niño Modoki and its possible teleconnection. J. Geophys. Res., 112, C11007, doi:10.1029/2006JC003798.

Bartlett, M., 1935: Some aspects of the time-correlation problem in regard to tests of significance. J. Roy. Stat. Soc., 98, 536-543.

Botjrke, W., 1974: A multi-level spectral model. I. Formulation and hemispheric integrations. Mon. Wea. Rev., 102, 687-701.

Cai, W., P. van Rensch, T. Cowan, and A. Sullivan, 2010: Asymmetry in ENSO teleconnection with regional rainfall, its multidecadal variability, and impact. J. Climate, 23, 4944-4955.

Cook, K. H., 2008: Climate science: The mysteries of Sahel droughts. Nat. Geosci., 1, 647-648.

Cornejo-Garrido, A. G., and P. H. Stone, 1977: On the heat balance of the Walker circulation. J. Atmos. Sci., 34, 1155-1162.

Feng, J., J. Li, and Y. Li, 2010: A monsoon-like southwest Australian circulation and its relation with rainfall in southwest Western Australia. J. Climate, 23, 1334-1353.

, - — , and H. Xu, 2013: Increased summer rainfall in northwest Australia linked to southern Indian Ocean climate variability. J. Geophys. Res., 118, 467-480, doi:10.1029/2012JD018323.

Gill, A. E., 1980: Some simple solutions for heat-induced tropical circulation. Quart. J. Roy. Meteor. Soc., 106, 447-462.

Gong, D.-Y., and C.-H. Ho, 2002: Shift in the summer rainfall over the Yangtze River valley in the late 1970s. Geophys. Res. Lett., 29, doi:10.1029/2001GL014523.

Haylock, M., and N. Nicholls, 2000: Trends in extreme rainfall indices for an updated high quality data set for Australia, 1910 1998. Int. J. Climatol., 20, 1533-1541.

Hendon, H. H., D. W. J. Thompson, and M. C. Wheeler, 2007: Australian rainfall and surface temperature variations associated with the Southern Hemisphere annular mode. J. Climate, 20, 2452-2467.

Ho, C.-H., J.-Y. Lee, M.-H. Ahn, and H.-S. Lee, 2003: A sudden change in summer rainfall characteristics in Korea during the late 1970s. Int. J. Climatol., 23, 117-128.

Hoerling, M., J. Hurrell, J. Eischeid, and A. Phillips, 2006: Detection and attribution of twentieth-century northern and southern African rainfall change. J. Climate, 19, 3989-4008.

Hu, Z.-Z., S. Yang, and R. Wu, 2003: Long-term climate variations in China and global warming signals. J. Geophys. Res., 108, 4614, doi:10.1029/2003JD003651.

Hung, C. W., and M. Yanai, 2004: Factors contributing to the onset of the Australian summer monsoon. Quart. J. Roy. Meteor. Soc., 130, 739-758.

Kistler, R., and Coauthors, 2001: The NCEP-NCAR 50-Year Reanalysis: Monthly means CD-ROM and documentation. Bull. Amer. Meteor. Soc., 82, 247-268.
Kug, J. S., F. F. Jin, and S. I. An, 2009: Two types of El Niño events: Cold tongue El Niño and warm pool El Niño. J. Climate, 22, 1499-1515.

Kumar, K. K., B. Rajagopalan, and M. A. Cane, 1999: On the weakening relationship between the Indian monsoon and ENSO. Science, 284, 2156-2159.

Levitus, S., T. Boyer, and J. Antonov, 1994: Interannual Variability of Upper Ocean Thermal Structure. Vol. 5, World Ocean Atlas 1994, NOAA Atlas NESDIS 5, $176 \mathrm{pp}$.

Li, J., and Q. Zeng, 2000: Significance of the normalized seasonality of wind field and its rationality for characterizing the monsoon. Sci. China, 43D, 646-653.

— , and - 2002: A unified monsoon index. Geophys. Res. Lett., 29, doi:10.1029/2001GL013874.

— distribution of the global monsoons. Adv. Atmos. Sci., 20, 299-302.

— - J. Feng, and Y. Li, 2012: A possible cause of decreasing summer rainfall in northeast Australia. Int. J. Climatol., 32, 995-1005.

Li, Y., J. Li, and J. Feng, 2012: A teleconnection between the reduction of rainfall in southwest Western Australia and north China. J. Climate, 25, 8444-8461.

Lin, Z., and Y. Li, 2012: Remote influence of the tropical Atlantic on the variability and trend in north west Australia summer rainfall. J. Climate, 25, 2408-2420.

Lo, F., M. C. Wheeler, H. Meinke, and A. Donald, 2007: Probabilistic forecasts of the onset of the north Australian wet season. Mon. Wea. Rev., 135, 3506-3520.

Manton, M. J., and J. L. McBride, 1992: Recent research on the Australian monsoon. J. Meteor. Soc. Japan, 70, 275-285.

Mantua, N. J., S. R. Hare, Y. Zhang, J. M. Wallace, and R. C. Francis, 1997: A Pacific interdecadal climate oscillation with impacts on salmon production. Bull. Amer. Meteor. Soc., 78, 1069-1080.

Martin, D. W., and W. D. Scherer, 1973: Review of satellite rainfall estimation methods. Bull. Amer. Meteor. Soc., 54, 661-674.

McBride, J. L., 1987: The Australian summer monsoon. Reviews of Monsoon Meteorology, C. P. Chang and T. N. Krishnamurti, Eds., Oxford University Press, 203-231.

Menzel, W. P., 2001: Cloud tracking with satellite imagery: From the pioneering work of Ted Fujita to the present. Bull. Amer. Meteor. Soc., 82, 33-48.

Nicholls, N., 2010: Local and remote causes of the southern Australian autumn-winter rainfall decline, 1958-2007. Climate Dyn., 34, 835-845.

Nitta, T., and S. Yamada, 1989: Recent warming of tropical sea surface temperature and its relationship to the Northern Hemisphere circulation. J. Meteor. Soc. Japan, 67, 375-383.

— , and Z. Z. Hu, 1996: Summer climate variability in China and its association with $500 \mathrm{hPa}$ height and tropical convection. J. Meteor. Soc. Japan, 74, 425-445.

North, G. R., T. L. Bell, R. F. Cahalan, and F. J. Moeng, 1982 Sampling errors in the estimation of empirical orthogonal functions. Mon. Wea. Rev., 110, 699-706.

Pyper, B. J., and R. M. Peterman, 1998: Comparison of methods to account for autocorrelation in correlation analyses of fish data Can. J. Fish. Aquat. Sci., 55, 2127-2140.

Rotstayn, L. D., and Coauthors, 2007: Have Australian rainfall and cloudiness increased due to the remote effects of Asian anthropogenic aerosols? J. Geophys. Res., 112, D09202, doi:10.1029/2006JD007712.

Santer, B. D., and Coauthors, 2000: Statistical significance of trends and trend differences in layer-average atmospheric temperature time series. J. Geophys. Res., 105 (D6), 7337-7356. 
Shi, G., W. Cai, T. Cowan, J. Ribbe, L. Rotstayn, and M. Dix, 2008: Variability and trend of north west Australia rainfall: Observations and coupled climate modeling. J. Climate, 21, 2938-2959.

Simmonds, I., 1985: Analysis of the "spinup" of a general circulation model. J. Geophys. Res., 90 (D3), 5637-5660.

—, and P. Hope, 1997: Persistence characteristics of Australian rainfall anomalies. Int. J. Climatol., 17, 597-613.

_ - and A. H. Lynch, 1992: The influence of pre-existing soil moisture content on Australian winter climate. Int. J. Climatol., 12, 33-54.

_ - A. Rocha, and D. Walland, 1992: Consequences of winter tropical pressure anomalies in the Australian region. Int. J. Climatol., 12, 419-434.

— D. Bi, and B. Yan, 1996: Relationships between summer rainfall over China and ocean temperatures in the tropical western Pacific. J. Meteor. Soc. Japan, 74, 273-279.

Smith, I., 2004: An assessment of recent trends in Australian rainfall. Aust. Meteor. Mag., 53, 163-173.

Smith, T. M., R. W. Reynolds, T. C. Peterson, and J. Lawrimore, 2008: Improvements to NOAA's historical merged land-ocean surface temperature analysis (1880-2006). J. Climate, 21, 2283-2296.

Taschetto, A. S., and M. H. England, 2009a: An analysis of late twentieth century trends in Australian rainfall. Int. J. Climatol., 29, 791-807.

—_, and — 2009b: El Niño Modoki impacts on Australian rainfall. J. Climate, 22, 3167-3174.

Trenberth, K. E., 1990: Recent observed interdecadal climate changes in the Northern Hemisphere. Bull. Amer. Meteor. Soc., 71, 988-993.

_ , and J. W. Hurrell, 1994: Decadal atmosphere-ocean variations in the Pacific. Climate Dyn., 9, 303-319.

Wang, B., 2006: The Asian Monsoon. Springer/Praxis Publishing, $787 \mathrm{pp}$.

Wardle, R., and I. Smith, 2004: Modeled response of the Australian monsoon to changes in land surface temperatures. Geophys. Res. Lett., 31, L16205, doi:10.1029/2004GL020157.

Webster, P. J., 1987: The elementary monsoon. Monsoons, J. S. Fein and P. L. Stephens, Eds., John Wiley, 3-32.

_ , V. O. Magaña, T. N. Palmer, J. Shukla, R. A. Tomas, M. Yanai, and T. Yasunari, 1998: Monsoons: Processes, predictability, and the prospects for prediction. J. Geophys. Res., 103 (C7), 14451-14510.

, C. A. Clayson, and J. A. Curry, 1996: Clouds, radiation, and the diurnal cycle of sea surface temperature in the tropical western Pacific. J. Climate, 9, 1712-1730.

Wu, G., and Coauthors, 1997: Global ocean-atmosphere-land system model of LASG (GOALS/LASG) and its performance in simulation study. Quart. J. Appl. Meteor., 8, 15-28.

- , and Coauthors, 2007: The influence of mechanical and thermal forcing by the Tibetan Plateau on Asian climate. J. Hydrometeor., 8, 770-789.

— Y. Yiu, B. He, Q. Bao, A. Duan, and F.-F. Jin, 2012: Thermal controls on the Asian summer monsoon. Sci. Rep., 2, 404, doi:10.1038/srep00404

Wu, T., P. Liu, Z. Wang, Y. Liu, R. Yu, and G. Wu, 2003: The performance of atmospheric component model R42L9 of GOALS/LASG. Adv. Atmos. Sci., 20, 726-742.

Xie, S. P., C. Deser, G. A. Vecchi, J. Ma, H. Teng, and A. T. Wittenberg, 2010: Global warming pattern formation: Sea surface temperature and rainfall. J. Climate, 23, 966-986.

Yatagai, A., and T. Yasunari, 1994: Trends and decadal-scale fluctuations of surface air temperature and precipitation over China and Mongolia during the recent 40 year period (19511990). J. Meteor. Soc. Japan, 72, 937-957.

Yu, R., and T. Zhou, 2007: Seasonality and three-dimensional structure of interdecadal change in the East Asian monsoon. J. Climate, 20, 5344-5355.

Zar, J. H., 1984: Biostatistical Analysis. Prentice Hall, 718 pp.

Zhang, R. H., and A. J. Busalacchi, 2005: Interdecadal change in properties of El Niño-Southern Oscillation in an intermediate coupled model. J. Climate, 18, 1369-1380.

- L. M. Rothstein, and A. J. Busalacchi, 1998: Origin of upperocean warming and El Niño change on decadal scales in the tropical Pacific Ocean. Nature, 391, 879-883.

Zhu, X. Y., J. H. He, and Z. W. Wu, 2007: Meridional seesaw-like distribution of the meiyu rainfall over the Changjiang-Huaihe River valley and characteristics in the anomalous climate years. Chin. Sci. Bull., 52, 2420-2428.

Zwiers, F. W., and H. v. Storch, 1995: Taking serial correlation into account in tests of the mean. J. Climate, 8, 336-351. 